\title{
Zur Kenntnis der Struktur der Niederblätter und Hochblätter einiger Laubhölzer.
}

\author{
Von Paul Neese (Kiel). $†$ \\ (Mit 11 Abbildungen im Text.)
}

\section{Aufgabe.}

Die folgende Untersuchung gilt zwei Fragen, die mehr formal als inhaltlich zueinander in Beziehung stehen. Beide Fragen hängen durch die Übereinstimmung des Materials und der Arbeitsmethode zusammen, da es sich in beiden Fällen um vergleichend morphologische und anatomische Untersuchung von Knospenschuppen und verwandten Blattformen an Sprossen von Laubhölzern handelt.

Die ers te Frage, deren Beantwortung weniger Raum beansprucht, ging von folgenden Gesichtspunkten aus: Eine Reihe von Holzgewächsen zeigt eine Differenzierung in fertile und sterile Sprosse, die oft soweit geht, daß die Blütensprosse überhaupt keine Laubblätter ausbilden und sich mehr oder weniger frühzeitig vor den Laubsprossen entfalten. Diese Unterschiede beider Sproßarten machen sich bereits in Form und Größe der Winterknospe bemerkbar, wie dies jedem Gärtner bekannt ist: die Blütenknospen sind meist größer, eventuell auch anders geformt als die Laubknospen. Indessen genauer sind die morphologischen Verhältnisse beider Knospenarten meines Wissens noch nicht miteinander verglichen worden, und dies gilt noch mehr für die anatomischen Eigenschaften. Deshalb lag es nahe, an einer Reihe von Gewächsen beide Knospenarten nach diesen Gesichtspunkten vergleichend gegenüberzustellen. Die aufgefundenen Unterschiede drängten weiter die Frage auf, welche Beziehungen zwischen den Besonderheiten der Form und Struktur einerseits und den jeder Knospenart eigentümlichen Lebensbedingungen und Funktionen andererseits existieren.

Wesentlich ausgedehnter waren die Untersuchungen bei der $\mathrm{z}$ weite $\mathrm{n}$ Frage, die den inneren Bau der Knospenschuppen und vor allem der auf diese oft folgenden Übergangsblätter, daneben auch bestimmter hochblattartiger Formen zum Gegenstand hat. Wenn auch an den Laubsprossen der meisten Holzgewächse auf die Tegmente unmittelbar die Laubblätter folgen, wird doch in vielen Fällen der Übergang zu diesen durch besondere Blattgebilde vermittelt, die mit zunehmender Insertionshöhe reicher gegliedert und größer werden und 
früher oder später in dem Laubblattypus endigen. Diese Zwischenformen haben von jeher das Interesse des Morphologen erregt, da sie besonders brauchbare Anhaltspunkte für die morphologische Wertung der Knospenschuppen liefern. Eine anatomische Untersuchung dieser Formen existiert, soweit ich sehen kann, nicht. Deshalb schien es von Interesse, die innere Struktur dieser Formen etwas eingehender zu behandeln, insbesondere zu verfolgen, in welcher Weise und nach welcher Gesetzmäßigkeit der Fortschritt der Gewebedifferenzierung innerhalb der Blattreihe sich vollzieht. Als besonderer Gesichtspunkt kam hierbei noch in Betracht, inwieweit sich beim Verfolg dieser Blätter sproßaufwärts etwa Beziehungen zwischen den einzelnen Gewebearten unter sich sowie zwischen dem inneren Bau und den äußeren Eigenschaften ergeben. Fernerhin galt es festzustellen, wie sich die Übergangsblätter in bezug auf gesetzmäßige Veränderungen bestimmter anatomischer Merkmale verhalten, wie sie neuerdings Nordhausen in Parallele zu den äußeren Formunterschieden beim Verfolg der Laubblattreihe von der Sproßspitze bis zur Basis fand, beispielsweise derart, daß bei bestimmten Laubsprossen der wellenförmige Verlauf der von der Fläche gesehenen radialen Epidermiswände sich graduell verstärkt. Lassen sich diese Gesetzmäßigkeiten weiterhin auch in der Zone der Zwischenformen verfolgen? Haben wir bei den jüngsten Knospenschuppen beginnend, eine kontinuierliche Reihe fortschreitender Umbildung der Struktur vor uns? Eigentlich sollte dies in Analogie zu den morphologischen Verhältnissen ohne weiteres erwartet werden. Tatsächlich ist dies durchaus nicht immer der Fall: nach der angeführten Gesetzmäßigkeit z. B. müßten die jüngsten Schuppen den stärksten Grad der Epidermiswellung aufweisen, während im Gegenteil ihre Epidermiswände vollkommen glatt verlaufen.

Im Prinzip haben ähnliche Fragen, wie sie soeben für die Blattgebilde der basalen Sproßpartien entwickelt wurden, auch Geltung für bestimmte hochblattartige Formen der oberen Achsenregion. Deshalb wurden auch diese in den Bereich der Untersuchungen gezogen.

\section{Teil.}

\section{Vergleichende Untersuchungen an Laub- und Blütenknospen.}

Die Bauverhältnisse der Knospenhülle sind in ihren wesentlichen Zügen hinreichend bekannt, es ist daher überflüssig, an dieser Stelle näher auf sie einzugehen. Die einzelnen Schuppen bestehen aus wenig differenziertem Gewebe mit einer meist derb ausgebildeten Epidermis und werden nur von primitiven Leitbündeln durchzogen. Genauere 
Arbeiten über das Bild der Knospenhülle als Ganzen, Zahl, Anordnung, äußere Beschaffenheit und morphologischen Charakter der sie aufbauenden Einzelschuppen bei den einzelnen Gewächsen haben Henry, Feist, Goebel, Lubbock u. a. geliefert; sorgfältige Untersuchungen an dem inneren Bau der Tegmente haben Mikosch, Cadura, C. G. R. Schumann, Grüßu. a. ausgeführt.

Gegenstand der folgenden Untersuchung waren die Pflanzen: Salix Caprea, Ulmus effusa Willd., Magnolia speciosa, Hamamelis virginiana, Fothergilla involucrata, Fothergilla Gardeni, Parottia persica, Prunus avium, Daphne Mezereum, Cornus mas, sämtlich Pflanzen, die als Frühblüher, zum Teil als Winterblüher, bekannt sind. Die Knospen wurden durchweg in frischem Zustande während der Winterperiode untersucht, während welcher sie ja nur geringes Wachstum zeigen, zur Ergänzung und zum Vergleich in einigen Fällen auch im austreibenden Zustande.

\section{Salix Caprea.}

Die Hülle der Laub- und Blütenknospen wird von zwei transversal stehenden, reduzierten Blättern gebildet, die miteinander zu einer derben Kapuze von gelbbrauner Farbe verwachsen sind. Die Blütenknospe unterscheidet sich von der Laubknospe äußerlich durch ihren größeren Umfang. Dementsprechend sind auch ihre Hüllblätter größer als die der Laubknospe, jedoch von gleicher Dicke wie diese. Mit der größeren Breite der Blütentegmente korrespondierend erscheinen ihre Grundgewebezellen in der Querrichtung ein wenig mehr gestreckt als die der Laubtegmente. Alle ihre Zellen sind tot und enthalten braunen Inhalt, während in den Schuppen der Laubknospe allgemein die Desorganisation der Zellinhalte nicht so weit fortgeschritten und eine Bräunung der Zellinhalte nur in den Leitbündeln wahrzunehmen ist.

Die Luftspalten, die alle Knospenschuppen parallel zur Außenfläche durchsetzen, sind mit Kalziumoxalatdrusen angefüllt. Bemerkenswert ist hierbei, daß auf die Blattflächeneinheit beim Laubtegment dreimal so viel Drusen wie beim Blütentegment entfallen.

\section{Ulmus effusa Willd.}

Die Laubknospen sind spitz, die Blütenknospen hingegen rundlich und zugleich umfangreicher als jene. Die Tegmente beider Knospenarten unterscheiden sich nicht hinsichtlich ihrer Zahl, und auch ihre Größe, die mit der Insertionshöhe beträchtlich zunimmt, ist bei entsprechenden Tegmenten etwa gleich. Sie stellen Stipeln dar, von denen 
die untersten 9-10 Paare verwachsen und zweizeilig angeordnet sind. Die obersten Tegmente zerfallen dann in ihre Stipelpaare, wodurch ihre zweizeilige Anordnung aufgehoben wird; zugleich hiermit treten in der Laubknospe die ersten Laubblattanlagen auf, während sich Blüten bereits in der Achsel des sechsten bis achten Blütentegments vorfinden.

Hinsichtlich ihrer Struktur zeigen die inneren Laub- und Blütentëgmente einen bemerkenswerten Unterschied. Bei beiden Knospenarten sind zunächst die äußeren Schuppen in ihrer ganzen Ausdehnung verholzt und derb; bei der vierten oder fünften Schuppe tritt dann am Grunde eine hellere, zarte Zone auf, die um so größer ist, je höher die Schuppe inseriert ist, bis schließlich die letzten Schuppen auch an der Spitze kaum noch gebräunt erscheinen. Während nun die unverholzte Basalzone der inneren Laubtegmente relativ groß und saftig bleibt, zeigt sie bei den entsprechenden Blütentegmenten geringere Ausdehnung und ist mehr oder weniger vertrocknet. Vergleicht man beispielsweise die neunte Schuppe der Laubknospe mit dem neunten Blütentegment, so zeigt sich jene Schuppe in ihrer ganzen Ausdehnung ausgesprochen grün und saftig, während das Blütentegment oberhalb des bräunlichgrünen, basalen Teils einen breiten, verholzten Rand aufweist, der bis zur Mitte der Schuppe reicht.

Diese im Laufe des Winters festgestellten Unterschiede bedingen nun auch das verschiedene Verhalten beider Knospenarten beim Austreiben. Während die Laubtegmente vermöge der lebend erhaltenen grünen Basalzone nachwachsen und den jungen Sproß eine Zeitlang schützen, werden die Blütentegmente, bei denen ein Nachwachsen nicht stattfindet, durch die schwellenden Blütensprosse mechanisch nach außen gedrängt und abgebogen.

\section{Magnolia speciosa.}

Die endständigen Blütenknospen unterscheiden sich auf den ersten Blick durch ihren viel größeren Umfang von den Laubknospen. Als Knospendecke fungiert bei beiden Knospenarten eine einfache, ringsum geschlossene, sackförmige Hülle, die vollständig mit einem filzigen Haarkleid bedeckt ist. Ihrem morphologischen Charakter nach besteht diese Hülle in der Hauptsache aus den Nebenblättern eines Laubblattes, dessen Abbruchsnarbe man an der Knospenhülle auf einem verdickten Mittelstrange findet.

Mit dem größeren Umfang der Blütenknospe verbindet sich eine voluminösere Bauart ihrer Hülle. Dies tritt einmal schon darin zutage, daß die Blütenknospenhülle etwa anderthalbmal so dick wie die Hülle 
der Laubknospe ist, beide an entsprechenden Stellen gemessen. Dann auch darin, daß auf den Blütenhüllen die Haare länger und von größerem Lumen als auf den Laubknospenhüllen sind. Bei beiden Knospenarten sind die Haare übrigens verholzt und ihre Zellinhalte abgestorben. Im Gegensatz zu der voluminösen Bauart der Blütenhülle besitzt die Laubknospenhülle eine gedrungene, feste Struktur. Dies zeigt sich im Querschnitt recht deutlich, wenn man die Außenseite der Knospenhüllen ins Auge faßt: in der Laubknospenhülle zeichnen sich die subepidermalen Zellschichten der Außenseite durch verdickte Wände und kleine Lumina aus, wohingegen die entsprechenden Zelllagen der Blütenhülle nur unverdickte Wände und relativ große Zelllumina aufweisen. Auch auf der Innenseite bemerkt man einen Strukturunterschied, der, allerdings weniger deutlich, den festeren Bau der Laubknospenhülle vor Augen führt. Allein am deutlichsten prägen sich sie Baueigentümlichkeiten in der Ausbildung, Zahl und Verteilung der Spikularzellen aus, die in Gestalt stark verholzter, verzweigter Sklerenchymzellen das Mesophyll durchsetzen. Diese sind in der Laubknospenhülle durchweg dickwandiger und englumiger, und ihre Zahl, auf die Flächeneinheit des Querschnittes bezogen, ist hier merklich größer. Sie liegen in der Laubknospenhülle meist zu mehreren in Nestern zusammen, wohingegen sie in der Blütenknospendecke zum größeren Teil vereinzelt angetroffen werden. Ich möchte nicht unerwähnt lassen, daß sich Unterschiede auch finden in bezug auf die Zahl der einzelligen Sekretschläuche, die im Grundgewebe eingebettet sind; diese sind nämlich in der Laubknospenhülle erheblich zahlreicher: ihre Zahl in der Laubknospenhülle verhält sich zu der in der Blütenknospenhülle wie $70 \mathrm{zu} 45$.

Bei Magnolia Campbelli (Laubknospe), M. Kobus, M. acuminata, M. tripetala beobachtete ich im Winter an mehreren Knospen, daß die alte Hülle abgeworfen wurde, so daß der Knospenschutz auf die nächste Hülle überging. Ich lasse die Frage offen, ob das Abwerfen als normal $\mathrm{zu}$ bezeichnen ist.

\section{Hamamelis virginiana.}

Die Blütenknospen haben etwa kugelige Form, die Laubknospen hingegen sind seitlich zusammengedrückt und schmal, und auffälligerweise im Ganzen etwas größer als jene. Während die Blütenknospe von einer Hülle lebender, typisch ausgebildeter kleiner Tegmente umgeben ist, bieten der Laubknospe die beiden abgestorbenen, kaum tegmentartig modifizierten Nebenblättchen des ältesten in der Knospe angelegten Laubblattes nur in unvollkommener Weise Schutz. Dieser 
wird jedoch erhöht durch den dichten Filz brauner Büschelhaare, der die Laubknospe vollständig überzieht und dem gegenüber das Haarkleid der Blütentegmente nur dürftig erscheint. Dem morphologischen Charakter nach darf man übrigens wahrscheinlich auch die Blütentegmente als Nebenblätter - allerdings ohne Spreitenteil — auffassen, da häufig je zwei am Grunde zusammenhängen.

Das parenchymatische, wenig verdickte Grundgewebe beider Tegmentarten weist einen bemerkenswerten Unterschied auf: im Laubtegment findet sich auf der Außen- oder Phloemseite eines jeden Leitbündels ein gut ausgebildeter, sichelförmiger Belag stark verdickter, faserig gestreckter, unverholzter Zellen, der im Blütentegment gänzlich fehlt. Auch bezüglich der Spaltöffnungen verhalten sich die Blütentegmente anders wie die Laubtegmente: auf jenen fehlen sie ganz, auf diesen treten sie unterseits ziemlich zahlreich auf.

\section{Parottia persica.}

Während die Blütenknospe groß und gerundet ist, erscheint die Laubknospe ziemlich klein, gestreckt und seitlich zusammengedrückt (Fig. 1). Der letzteren legen sich, wie bei Hamamelis, die vertrockneten Nebenblättchen des ältesten Laubblattes beiderseits an, den wirksameren Knospenschutz bewirkt auch hier der filzige Überzug brauner Büschelhaare, der die ganze Laubknospe bedeckt. Die Blütenknospenhülle dagegen wird in vollkommenerer Weise aus mehreren Schuppen gebildet, von denen die oberen zugleich als Blütentragblätter fungieren. Die Tegmente sind hier viel größer und kräftiger als bei der Laubknospe, schon ihre Dicke ist anderthalbmal so groß wie die der Laubtegmente, dabei sind sie lebend und elastisch, während jene abgestorben, spröde und hinfällig sind. In eigentümlicher Weise weichen beide Tegmentarten in Bezug auf Anordnung und Größe der Haare voneinander ab. Während die beiden Laubtegmente beiderseits dicht mit
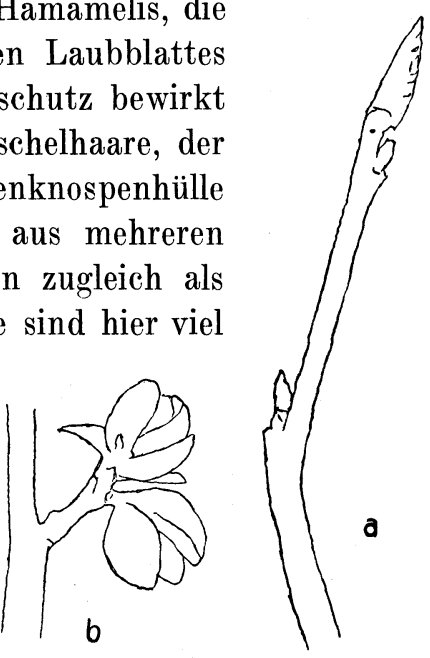

Fig. 1. Parottia persica. a Laubknospen, b Blütenstandsknospen. Etwas über natürliche Größe. Büschelhaaren besetzt sind, tragen die Blütentegmente solche fast nur auf der Außenseite, zuweilen auch auf der Innenseite ganz zerstreut an der Spitzenregion. Auffallender noch ist deren Form- und Größenunterschied: die die Büschelhaare zusammensetzenden Einzelhaare sind 
nämlich auf den Blütentegmenten etwa 20 mal so lang wie auf den Laubtegmenten; dabei ist das Lumen der Haare auf den Blütentegmenten schmaler (Fig. 2).

Das Grundgewebe beider Tegmentarten ist ein schwach verdicktes Parenchym. Spaltöffnungen wurden auf beiden nicht gefunden.

\section{Fothergilla.}

F. involucrata. Die schmalen Laubknospen sind bedeutend kleiner als die am Ende seitlicher Kurztriebe stehenden eiförmigen Blüten-

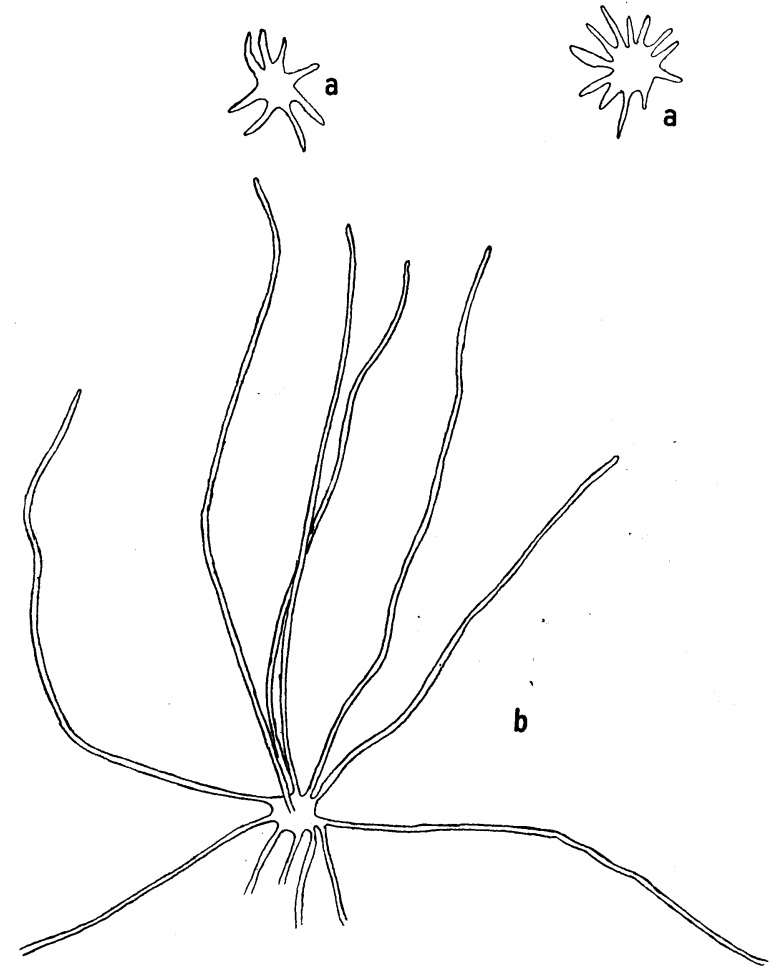

Fig. 2. Parottia persica. a a Büschelhaare von einem „Laubtegment", b Büschelhaare von einem „Blütentegment". Vergr. $100 / 1$. knospen. Auch bei Fothergilla besteht, wie bei Hamamelis, die Blatthülle der Laubknospen nur aus zwei hinfälligen Nebenblättchen zu beiden Seiten der Knospe, und auch hier wird der Hauptschutz durch den filzigen Haarüberzug der Knospe bewirkt. Die Tegmente der Blütenknospe werden von den Stipeln der normalen Laubblätter gebildet, die in der Blütenknospe am Grunde des Blütenstandes eingeschlossen sind; sobald die Stipeln des untersten Laubblattes abfallen, wird ihre Funktion von den Nebenblättern des nächsten, gegenüberstehenden Laubblattes übernommen. Der Unterschied beider Tegmentarten ist wesentlich ein quantitativer, indem die Blütentegmente durchweg größer und um eine Zellage dicker als die Laubtegmente sind. 
Die Gewebe der Laub- und Blütentegmente sind am Tegmentgrunde grün und lebend, in den oberen Teilen rotbraun und abgestorben, ohne daß die Zellwände verholzt oder verkorkt sind. Spaltöffnungen treten bei beiden ganz vereinzelt auf der Außenseite auf.

F. Gardeni. Die Bauverhältnisse der Knospenhüllen gleichen im allgemeinen denen von F. involucrata. Während indessen, bei jener Pflanze zu jedem die Blütenknospe deckenden Stipelpaar eine normale Laubblattspreite vorhanden ist, erscheint diese hier bei den beiden untersten Stipeln nicht größer als diese selbst und abgestorben, bei den folgenden Stipelpaaren fehlt sie überhaupt.

\section{Prunus avium.}

Die Laub- und Blütenknospen unterscheiden sich sowohl hinsichtlich ihrer Form als auch ihrer Größe: jene sind spitz, diese abgerundet und größer als jene. Im Gegensatz zu K. Schumann, der (pag. 42) die Laub- und Blütenknospen sorgfältig beschrieben hat, fand ich stets die Zahl der Blütentegmente erheblich größer als die der Laubtegmente. So zählte ich, von geringen Unterschieden in der Qualität der Hüllblätter absehend, im Januar an den Blütenknospen etwa 23, an den Laubknospen etwa 13 Tegmente, und im Frühjahr, kurz nach dem Öffnen der Knospe, an jenen 18-21, an diesen etwa 9.

Bei den Blütenknospen finden sich auf der Innenseite der letzten sieben Schuppen zahlreiche lange, verfilzte Haare, während auf der Innenseite der Laubtegmente die Haare nur kurz und wenig zahlreich sind. Bemerkenswerterweise ist die basale grüne Zone bei den Laubtegmenten besser erhalten als bei den entsprechenden Blütentegmenten. Einmal ist sie bei jenen größer; dann zeigen bei den Laubtegmenten die Gewebe der grünen Grundzone, besonders die mittleren Mesophyllschichten, im Querschnitt stets ein frischeres und intensiveres Grün.

Wie schon K. Schumann bemerkt, verhalten sich die innersten Tegmente recht verschieden, indem sie in den Blütenknospen Übergangsformen zu den Hochblättern, in den Laubknospen Übergangsformen zu den Laubblättern bilden. Die Übergangsformen zu den Hochblättern weichen in Gestalt und Nervatur stark von den tieferen Tegmenten $a b$ und erinnern durchaus an reduzierte Laubblätter. Die Übergangsformen zum Laubblatt zeigen oberhalb des relativ großen Scheidenteils die charakteristischen Stipelzipfel, zwischen denen sich ein kleines, mehr oder weniger ausgebildetes Laubblatt erhebt. 


\section{Daphne Mezereum.}

Die Blütenknospen lassen sich äußerlich leicht von den Laubknospen unterscheiden: jene sind stets seitenständig und abgestumpft und viel umfangreicher als die zum Teil endständigen, schmalen und spitzen Laubknospen. Die der Laubblattlamina homologen Tegmente sind bei den Blütenknospen, entsprechend dem größeren Umfange derselben, durchweg breiter als bei den Laubknospen, dagegen ist ihre Zahl merkwürdigerweise bei jenen nur etwa halb so groß wie bei diesen.

Wie bei Ulmus effusa Willd. verdient das Größen- oder Ausdehnungsverhältnis der verholzten, derben Tegmentpartien zu den frisch grünen oder häutigen, basalen Teilen bei beiden Knospenarten besondere Aufmerksamkeit. Die Verholzung der Tegmente, die übrigens bei beiden Knospenarten während des Winters fortschreitet, nimmt in der Laubknospenhülle größere Ausdehnung an als in der Hülle der Blütenknospe. In jener sind nämlich von den etwa 14 Tegmenten die sechs bis acht äußeren in ihrer ganzen Ausdehnung verholzt, bei den übrigen ist die verholzte Partie um so kleiner, je höher die Schuppe inseriert ist und schließlich auf die Spitze reduziert. Von den 4-6 Blütentegmenten sind nur die äußeren in ihrer ganzen Ausdehnung verholzt, die übrigen haben nur einen ziemlich breiten verholzten Rand. Während aber bei diesen die unverholzte basale Partie hellbraun und trockenhäutig ist, erscheint sie bei den Laubtegmenten frisch und grün und lebend.

Vergleicht man im Querschnitt die basale Zone eines Laubtegmentes mit der eines Blütentegmentes, so erweist sich das Grundgewebe in beiden Fällen als ein unverholztes, wenig verdicktes Parenchym; während jedoch beim Laubtegment die Zellen turgeszent und grün sind, erscheinen sie beim Blütentegment kollabiert, von gelbbraunem Inhalt angefüllt und offenbar nicht mehr teilungsfähig. Hiermit hängt es zusammen, daß die grüne Zone der Laubtegmente merklich dicker ist als die entsprechende häutige Zone der Blütentegmente.

Während ihrer Entfaltung zeigen beide Knospenarten das gleiche Verhalten wie bei Ulmus effusa Willd.: nur die Laubtegmente wachsen am Grunde nach, die Blütentegmente werden durch die schwellenden Blüten nach außen gebogen und fallen alsdann sehr bald ab.

\section{Cornus mas.}

Laub- und Blütenknospe unterscheiden sich schon äußerlich sehr merklich: die Laubknospe ist spitz und schmal, die Blütenknospe kugelig und umfangreicher als jene. Während die Laubknospen von zwei übrigens stets gegenständigen, am Grunde verwachsenen Schuppen bedeckt 
sind, besitzen die Blütenknospen eine wechselnde Zahl von Tegmenten; meist treten vier, seltener drei oder zwei Schuppenpaare auf. Schon hinsichtlich ihrer Form lassen sich die Tegmente unter zwei Typen gruppieren. $\mathrm{Zu}$ dem einen Typus, der durch schmale, kleine, aus breiter Basis spitz zulaufende Gestalt charakterisiert ist, zählen die Laubtegmente und außerdem die unterhalb der letzten vier Blütentegmente auftretenden Schuppen ${ }^{1}$ ); der andere Tegmenttypus ist durch elliptische bis rundliche, viel größere Form ausgezeichnet und findet sich ausschließlich bei den letzten vier Tegmenten der Blütenknospe. An der Spitze von Tegmenten der ersten Art findet man zuweilen deutlich eine verkümmerte Lamina, so daß diese Tegmente als dem Blattgrunde homologe Gebilde angesehen werden müssen. Ich möchte dies besonders hervorheben, weil Henry und Mikosch ihnen laminaren Charakter zuschreiben, wie er allerdings den Tegmenten von Cornus sanguinea auch nach meinen Beobachtungen zukommt. Beiläufig sei noch bemerkt, daß ich in den Fällen, wo die Blütenknospenhülle aus vier Schuppenpaaren besteht, in. den Achseln des zweiten Schuppenpaares stets sehr kleine Sproßvegetationspunkte mit zwei Blattanlagen fand.

Deutliche Unterschiede zeigen beide . Tegmentgruppen hinsichtlich der Nervatur (Fig. 3 und 4). Die als

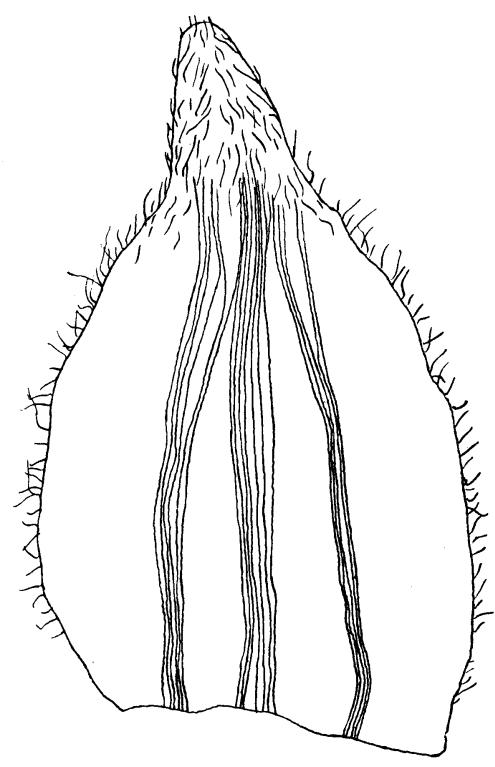

Fig. 3. Cornus mas. 2. Schuppe einer von vier Tegmentpaaren gedeckten Blütenknospe. Vergr. $50 / 1$.

kleiner und schmaler charakterisierten Tegmente weisen drei unverzweigte, symmetrisch angeordnete, nach der wulstigen Blattspitze zu konvergierende und sich in ihr vereinigende starke Nervenstränge auf, wohingegen der größere, elliptische Tegmenttypus eine höhere Zahl bogig verlaufender, schmälerer Nerven besitzt, die reichlich sich noch weiterhin verzweigende Seitennerven abgeben, ohne daß diese im allgemeinen miteinander anastomosieren. Man könnte bei dieser Beschaffenheit

1) Wo die Blütenknospe durch nicht mehr als vier Schuppen gedeckt ist, fehlen diese. 
der Nervatur geneigt sein, den letzten vier Blütentegmenten laminaren Charakter zuzuschreiben, wenn es eben nicht bedenklich wäre, die morphologische Wertbestimmung eines Organs auf seine anatomischen Eigenschaften zu gründen. Man wird die Verschiedenheit des Leit-
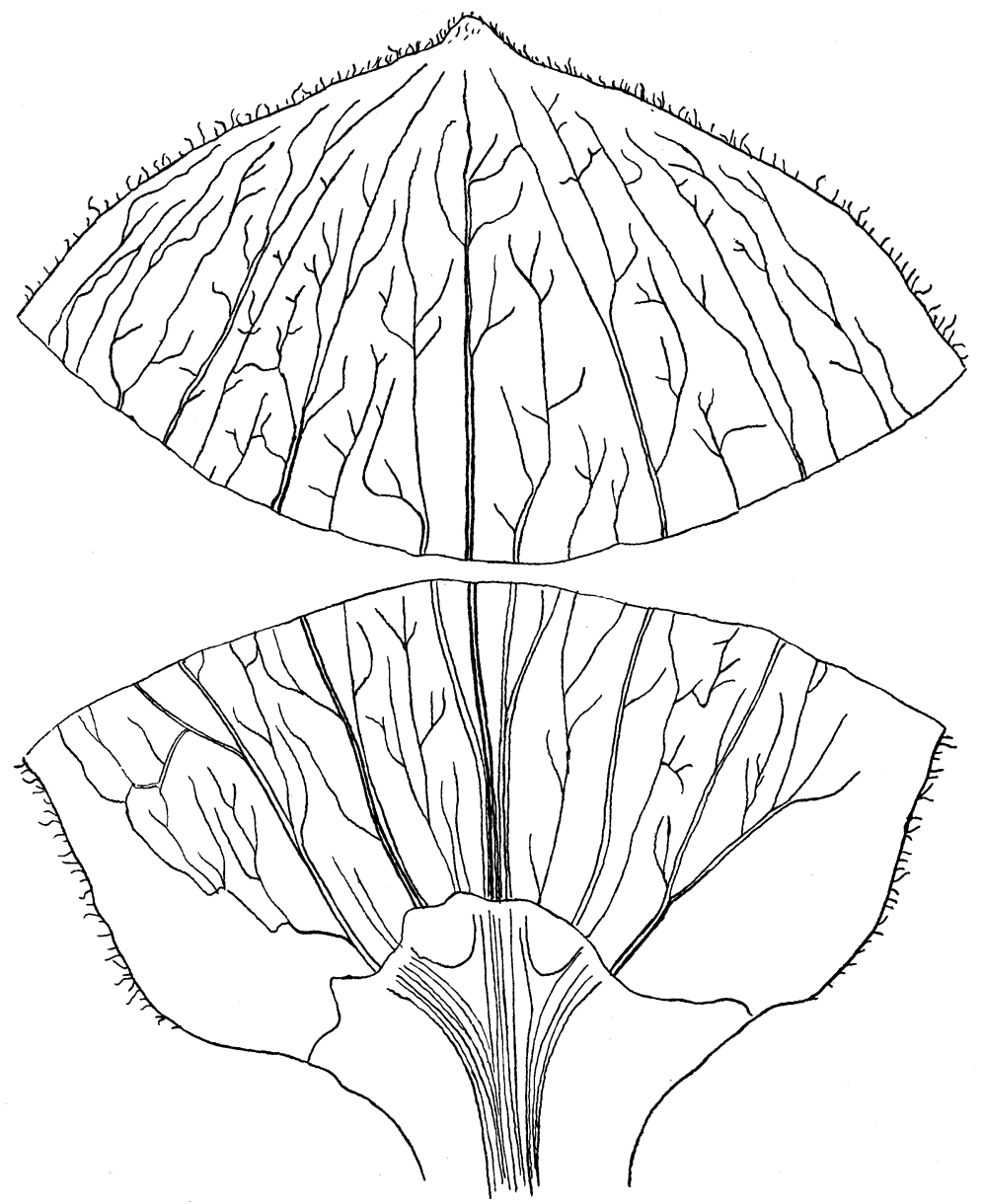

Fig. 4. Cornus mas. 3. Schuppe einer von vier Tegmentpaaren gedeckten Blütenknospe. Vergr. 50/1.

bündelverlaufs eher zu der Blattgröße und zu der damit wachsenden funktionellen Inanspruchnahme in Beziehung setzen dürfen.

Die anatomischen Unterschiede sind im übrigen geringfügig. Das Gewebe bleibt dauernd in lebendem Zustande und ist grün. Chloroplasten habe ich hier wie bei anderen Knospenschuppen nicht scharf erkennen können. Auf der Außenseite finden sich vereinzelt Spalt- 
öffnungen vor. Bemerkenswert ist, daß die Tegmente des größeren Typus reicher an Kristalldrusen sind.

\section{Zusammenfassung.}

Ich fasse die allgemeinen Ergebnisse der Untersuchungen kurz zusammen und füge dabei noch einzelne Beobachtungen ein.

Ganz allgemein zeigen die Laubknospen bei den untersuchten Pflanzen geringere Größe als die Blütenknospen. Dies Verhältnis gilt auch für die meisten anderen nicht weiter untersuchten Holzpflanzen, die im Winter Laub- und Blütenknospen tragen, z. B. Pyrus communis, Corylopsis spicata, Jasminum nudiflorum, für alle Arten von Salix und Magnolia und für viele Rhododendron-Arten. Nur bei Hamamelis virginiana, als einzigen Ausnahme, erscheinen die Blütenknospen als die kleineren.

Beim Vergleich der Form beider Knospenarten erscheinen die Laubknospen schmal und zugespitzt, die Blütenknospen dick und rundlich - jedenfalls stets dann, wenn diese einen Blütenstand einschließen. Beide Knospenformen deuten so die Tracht des künftigen Sprosses bereits an: überall, wo bei den untersuchten Frühblühern ein Blütenstand von einer Knospenhülle umgeben ist, hat dieser späterhin, im Gegensatz zum gestreckten Laubsproß, eine gestauchte Achse und breit ausladende Form. Eine nähere Betrachtung der Blütenstände ergibt, daß es sich immer um wenig umfangreiche köpfchenförmige Blütenstände handelt. Demnach suchen es offenbar die frühblühenden Gewächse im allgemeinen zu vermeiden, eine lange saftige Blütenstandsachse auszubilden, deren Festigkeit durch den Turgor bedingt wird und daher bei niederen Temperaturen versagen könnte.

Mit dem größeren Umfang der Blütenknospe steht im Zusammenhang, daß sehr oft die Zahl ihrer Tegmente größer als die der Laubknospe ist. Dies kann soweit gehen, daß sie etwa doppelt so viel Schuppen wie jene trägt (Prunus avium, Forsythia). Andere Pflanzen hingegen tragen den größeren Umfang der Blütenknospe durch gesteigerte Größe ihrer Tegmente Rechnung, wofür Magnolia ein deutliches Beispiel liefert.

In anatomischer Hinsicht zeigt sich, daß die Blütentegmente den Laubtegmenten quantitativ, besonders bezüglich der Dicke überlegen sein können, daß aber in anderen Fällen auch qualitative Unterschiede auftreten. Beispielsweise fehlen bei Hamamelis die Spaltöffnungen auf den Blütentegmenten, während sie auf der Außen- 
seite der Laubtegmente ziemlich zahlreich sind; zugleich weisen diese auf der Phloemseite der Leitbündel einen sichelförmigen Belag stark verdickter, gestreckter Zellen auf, der sich in den Blütentegmenten nicht vorfindet. Ein recht verschiedener Verlauf der Nervatur findet sich in den Laub- und Blütentegmenten von Cornus mas (Fig. 3 und 4). Ferner sind z. B. die Haare auf den Blütentegmenten von Parottia persica (Fig. 2) und Prunus avium anders gestaltet, vor allem viel länger und zählreicher als auf den Laubtegmenten. Wenn so einige Pflanzen größere Dicke oder bessere Behaarung gerade der Blütentegmente zeigen, läßt sich doch in bezug auf die übrigen anatomischen Unterschiede eine bestimmte Gesetzmäßigkeit nicht feststellen. Schließlich möchte ich noch die Unterschiede hervorheben, welche die unverholzte Basalzone beider Tegmentarten oft zeigt. Diese bleibt nämlich bei den inneren Laubtegmenten häufig bis zum Knospenbruch in mehr oder minder großer Ausdehnung grün und wachstumsfähig, während sie bei den Blütentegmenten mehr oder weniger vertrocknet.

Ausgehend von der Anschauung, daß die Blütenteile besonders empfindlich seien, wird man zu der Annahme geneigt sein, daß die Blütenknospenhülle vermöge ihres Baues größeren Schutz gewähre als die Hülle der Laubknospe. Dies ergibt sich auch in der Tat für eine Reihe untersuchter Pflanzen, wenn man die besonderen Bauverhältnisse beider Knospenarten, d. h. Zahl, Größe, Dicke und Behaarung ihrer Tegmente in ökologischer Hinsicht prüfend vergleicht. Inbetreff der übrigen Pflanzen hingegen kommt man zu dem Urteil, daß die größere Zahl, oder die größere Breite bzw. Dicke der Blütentegmente eben nur dem größeren Umfang der Blütenknospe entspricht. Wenn nun in dem einen Fall die Zahl, in dem anderen die Größe der Blütentegmente gesteigert erscheint, so sind mit diesen beiden typischen Mitteln offenbar verschiedene Zwecke verknüpft. Trägt die Pflanze dem größeren Umfang der Blütenknospe durch höhere Zahl der Blütentegmente Rechnung, so wird hierdurch der Hülle das Vermögen erteilt, die Gesamtform leichter zu ändern und sich der Gestaltsveränderung des Knospeninhalts beim beginnenden Frühjahrswachstum besser anzupassen. Wird dagegen unter Aufwendung der gleichen Materialmenge der andere Modus verwirklicht, dem größeren Umfang der Blütenknospe entsprechend die Tegmentgröße zu steigern, so wird vielleicht der Vorteil eines mehr lückenlosen Abschlusses der Knospe erreicht. Eine zeitlich länger hinausgedehnte Formanpassung der Hülle an den Knospeninhalt durch Nachwachsen der wachstumsfähig erhaltenen Grundzone der inneren Tegmente zeigen bei vielen Pflanzen 
(Daphne, Ulmus, Prunus avium, Prunus cerasifera, Prunus Sieboldi) nur die Laubknospen.

\section{Teil.}

\section{Über die Strukturänderungen des Laubblattes in seinen Über- gangsformen zu den Knospenschuppen und Ilochblättern.}

Wie schon aus der Überschrift und auch aus der Einleitung hervorgeht, handelt es sich um zwei Gruppen von Untersuchungsobjekten: es sollen einerseits die Übergangsstadien von den Knospenschuppen zu den Laubblättern, andererseits oberhalb der Laubblattregion auftretende hochblattartige Gebilde ihrem inneren Bau nach untereinander und mit den Laubblättern verglichen werden. Hierzu ist noch eine genauere Präzisierung und Abgrenzung beider Blattgruppen gegen die übrigen Blattgebilde erforderlich. Unter den Übergangsformen zwischen den Knospenschuppen und Laubblättern sind diejenigen Blattgebilde verstanden, die einerseits, im Gegensatz zu den eigentlichen Tegmenten, während der Winterperiode vollkommen in der Knospenhülle eingeschlossen waren, andererseits in ihrer vollen Ausbildung doch noch nicht alle charakteristischen Teile des Laubblattes, vor allem nicht dessen Größe aufweisen, im Gegenteil noch in ihren einzelnen Teilen Tegmentcharakter tragen können ${ }^{1}$ ).

Aus der Reihe der hochblattartigen Formen wurden nur die dauernd chlorophyllgrünen untersucht, Blattgebilde also, die vielleicht nicht zu den typischsten Hochblättern zu rechnen sind, die sich jedoch sowohl durch Größe und Form als auch dadurch, daß sie Tragblätter von Blüten oder Teilblütenständen darstellen, als solche charakterisieren; auch sie stammen von Holzpflanzen.

Von vornherein war selbstverständlich die Forderung zu beachten, daß Blattformen, um miteinander vergleichbar zu sein, denselben morphologischen Charakter besitzen müssen. Da es nun darauf ankam, die besagten Blattformen nicht nur untereinander, sondern auch mit der Laubblattspreite zu vergleichen, so galt für die Auswahl der zu untersuchenden Arten das Prinzip, daß die Übergangsformen an der

1) Auch die so definierten Übergangsblätter können mit einem gewissen Recht als Tegmente bezeichnet werden, da auch sie zum Schutz der ruhenden Knospe beitragen, so daß eine scharfe Grenze gegen die eigentlichen Tegmente nicht zu ziehen ist. Da die Struktur dieser Übergangsblätter, besonders der unteren, oft nur aus der der Tegmente verstanden werden kann, wurden auch diese stets in den Bereich der Untersuchung gezogen. 
Sproßbasis und ebenso die Hochblattformen der Laubblattspreite homolog sein müssen. In zwei Fällen (Rubus, Rosa) wurden zur Untersuchung auch solche Hochblätter herangezogen, die zwar in ihrer geringeren oder größeren Ausdehnung Scheidencharakter tragen, die aber an der Spitze einen mehr oder minder großen Spreitenteil aufweisen, der dann allein zum Vergleich diente.

Da ich es nicht als meine Aufgabe betrachte, die anatomischen Verhältnisse der zahlreichen Einzelblattypen rein deskriptiv zu schildern, sondern vielmehr den Hauptwert darauf lege, die Strukturveränderungen innerhalb ganzer Blattreihen zu verfolgen, so gebe ich zur Vermeidung unnötiger Breite nicht die Menge der einzelnen Beobachtungsdaten wieder, die naturgemäß zur Konstatierung jener Strukturänderungen notwendig waren, sondern beschränke mich auf eine zusammenfassende Darstellung, die noch dadurch erleichtert wird, daß das Verhalten der Pflanzen ziemlich übereinstimmt.

\section{Morphologisches.}

Zum Verständnis des folgenden ist es vorteilhaft, sich die morphologischen Verhältnisse der Übergangsblätter an der Sproßbasis und der hochblattartigen Gebilde zu vergegenwärtigen. Wir gehen aus von den Knospenschuppen, die entsprechend ihrer Funktion meist um so kleiner, zugleich auch um so derber und fester erscheinen, je älter sie sind, und deren innere Struktur relativ zu der des Laubblattes ziemlich undifferenziert ist. Bei den weitaus meisten Pflanzen, deren Übergang'sblätter an der Sproßbasis untersucht wurden, sind die Knospenschuppen von bräunlich grünem oder schmutzig grünem Ton, ihre Zellinhalte zeigen nicht jene rotbraune Färbung und Zusammenballung, wie sie für abgestorbene Gewebe charakteristisch sind. Nur die Tegmente von Forsythia suspensa und Salix pentandra sind braun und tot.

Die auf die Knospenschuppen folgenden Blattgebilde stellen, soweit sie vorhanden sind, nach Form und Größe allmählich fortschreitende Übergänge zu den Laubblättern dar (Fig. 5). Meist sitzen sie der Sproßachse mit breiter Basis auf, erst bei den jüngeren, größeren ist ein Stiel angedeutet. Hinsichtlich ihrer Konsistenz ist hervorzuheben, daß die unteren bisweilen eine ähnliche Textur wie die Tegmente aufweisen, während die oberen häufig recht zart erscheinen. Ihre Funktion ist geteilt: sie dienen einerseits den jüngeren Sproßteilen als Schutz, sowohl innerhalb der geschlossenen Knospe als auch noch während der Entwicklung des Sprosses, andererseits befähigt sie ihr Chlorophyllgehalt zur Assimilation. Sowie jedoch der eigentliche Assimilationsapparat in 
Gestalt der Laubblätter entwickelt ist, im Laufe des Mai etwa, fallen sie meist ab.

Der Übergang zur Laubblattregion vollzieht sich bei den einzelnen Pflanzen verschieden schnell. Unter den untersuchten Pflanzen besitzen Salix pentandra und Diervillea sessilifolia nur wenig Übergangsblätter, zahlreicher, zu dreien bis vieren bzw. drei bis vier Paaren, finden sie sich bei Chionanthus virginica, Forsythia suspensa, Syringa vulgaris, Lonicera Ccaprifolium, Ilex integra, Rhus Cotinus, Ligustrum vulgare; recht viele Übergangsblätter schließlich finden sich an kräftigen Sprossen von Spiraea Billiardi.

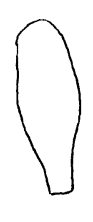

a

In der Reihe der hochblattartigen Formen, die sich bei den untersuchten

Pflanzen ohne sprunghafte Größenabnahme an die Laubblattzone anschließt, nimmt in der Regel die Blattgröße mit der Insertionshöhe allmählich ab, zugleich wird die Form einfacher, der Blattstiel wird kürzer und schwin-

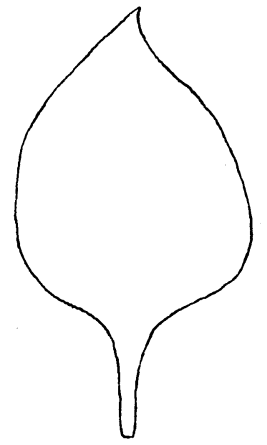

p

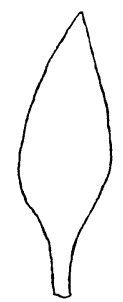

b

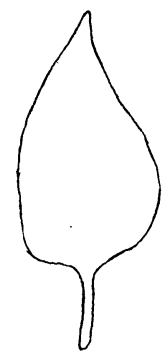

c
Fig. 5. Syringa vulgaris. a, b, c aufeinanderfolgende Übergangsblätter von der Basis eines Sprosses. p, q, r aufeinanderfolgende Hochblätter aus dem Blütenstand. Natürliche Größe. det schließlich meistens, kurzum, es findet eine ähnliche Reduktion statt wie bei den Übergangsblättern an der Sproßbasis (Fig. 5). Diese Blattformen waren immer nur soweit Gegenstand der Untersuchung, als sie reichlich Blattgrün führen und also als durchaus assimilationsfähig gelten dürfen, wenn auch in geringerem Maße als das Laubblatt. Denn soweit erscheint auch ihre Funktionsgleichheit mit dem Laubblatt gewährleistet, die als eine Bedingung für die Vergleichbar- 
keit der Blattstrukturen zu gelten hat. Neben der assimiliernden Tätigkeit fällt den hochblattartigen Formen als Hauptfunktion der Schutz der sich entwickelnden Blütensprosse zu.

Die untersuchten hochblattartigen Gebilde tragen in ihrer ganzen Ausdehnung Spreitencharakter bei Syringa vulgaris, Rhus Cotinus, Ligustrum vulgare, Hydrangea paniculata, Spiraea Douglasii, Syringa Emodi, Weigelia amabilis Carr. Daneben wurden noch die oberhalb der Laubblattregion stehenden Übergangsblätter zu den Knospenschuppen von Rhododendron praecox untersucht, Blattgebilde, die, da hauptsächlich Blütenknospen in Betracht kamen, im Folgenden zu den hochblattartigen Formen gestellt sind, die allerdings mit einigem Recht auch zu den Übergangsformen zwischen Knospenschuppen und Laubblättern gerechnet werden könnten; naturgemäß kamen auch diese nur soweit in Betracht, als sie noch in ihrer ganzen Ausdehnung Spreitencharakter trugen, was bei den oberen nicht mehr zutrifft.

In stärkerem Maße ist der Blattgrund bei Rubus plicatus an der Bildung der Hochblätter beteiligt, hier findet sich nur an der Spitze eine größere oder kleinere Lamina, die allein Gegenstand der Untersuchung war. Hier können weiterhin noch Rosa (Kulturform) und Mespilus germanica angeschlossen werden, deren mit Hochblättern innerlich verwandte Kelchzipfel hauptsächlich zur Beantwortung einer bestimmten Frage in den Bereich der Untersuchung gezogen wurden. Diese Kelchzipfel ordnen sich hinsichtlich ihrer Größe in die Blattstellung :schraubenlinie ein, derart, daß das letzte Kelchblatt das kleinste ist; sie tragen bei Mespilus vollständig Spreitencharakter, während sie bei Rosa wesentlich dem Blattgrunde entsprechen, dem eine unter Umständen recht große, scharf abgesetzte Lamina aufsitzt, die allein Gegenstand der Untersuchung war. -

Um im allgemeinen ein zusammenhängendes Bild von der Veränderung einer Blatteigenschaft längs des ganzen Sprosses zu gewinnen, erschien es praktisch, am Ende jedes Abschnitts die Gesetzmäßigkeiten, die sich innerhalb der Reihe der basalen Übergangsblätter und der Hochblattformen auffinden ließen, miteinander und mit denjenigen zu kombinieren, die Nordhausen und auch Schramm und Yapp beim Verfolg der Strukturveränderungen in der Laubblattreihe festgestellt haben. Hinsichtlich der Laubblattreihe konnten für diese Kombination naturgemäß nur die Angaben über periphere, somit einigermaßen hell belichtete Sprosse in Betracht kommen, denn nur solche setzen sich bei unsern Pflanzen in Blütenstände fort und bilden also oberhalb der Laubblattzone jene Hochblattformen aus. 


\section{Blattdicke.}

Zur Orientierung darüber, in welchem Sinne sich innerhalb der Region der Knospenschuppen die Blattdicke ändert, wurde diese an dem Beispiel von Syringa vulgaris für alle Tegmentpaare vom ersten bis aufwärts zum letzten festgestellt. Wir erhalten für die einzelnen Tegmentpaare $\mathrm{T}$, indem wir ihre Dicke in der Schuppenmitte messen, die Werte $\mathrm{T}(1) 800 \mu, \mathrm{T}(2) 640 \mu, \mathrm{T}(3) 580 \mu, \mathrm{T}(4) 575 \mu$ und für das erste Übergangsblattpaar Ü(1) $470 \mu$ (s. die Anmerkung). Die Blattdicke nimmt also mit der Insertionshöhe der Schuppen stark ab.

Tabelle $\mathbf{I}^{1}$ ).

\begin{tabular}{c|c|c|c|c}
\hline \hline & Syringa vulgaris & $\begin{array}{c}\text { Chionanthus } \\
\text { virginica }\end{array}$ & $\begin{array}{c}\text { Salix } \\
\text { pentandra }\end{array}$ & $\begin{array}{c}\text { Forsythia } \\
\text { suspensa }\end{array}$ \\
\hline $\mathrm{T}(\mathrm{n})$ & 457 & 140 & 178 & 62 \\
$\mathrm{Ü}(1)$ & 417 & 170 & 72 & 99 \\
$\ddot{U}(2)$ & 214 & 131 & 123 & 155 \\
$\dddot{U}(3)$ & 164 & 105 & - & 203 \\
$\ddot{U}(4)$ & - & -118 & 160 & 249 \\
$\mathrm{~L}(1)$ & 219 & & & 250
\end{tabular}

Wie die Tabelle I zeigt, setzt sich bei Syringa vulgaris diese Dickenabnahme in die Region der Übergangsblätter hinein fort bis zum letzten (dritten) Übergangsblatt, während das ers te Laubblatt wieder erheblich dicker wird. Auch bei Chionanthus virginica und Salix pentandra liegt an der Sproßbasis das Minimum der Blattdicke innerhalb der Zone der Übergangsblätter: bei jener Pflanze zeigt das letzte (dritte), bei dieser das erste Übergangsblatt ein Minimum der Blattdicke. Etwas anders verhält sich Forsythia susponsa, indem hier die Blattdicke vom letzten

1) Erläuterung zu den Tabellen. Maßangaben in $\mu$. Es bedeuten: T Tegment, Ü Übergangsblatt an der Sproßbasis, L Laubblatt, H Hochblattform, Oe obere Epidermis, Ue untere Epidermis. Die in Klammern gesetzten Zahlen hinter diesen Buchstaben geben die Blattnummer in der Richtung von der Basis zur Spitze an, $\mathrm{n}$ bedeutet letztes Blatt der betreffenden Blattart. Die Tatsache, daß beim Verfolg der Hochblattformen sproßaufwärts nicht immer jedes der oft recht zahlreichen aufeinanderfolgenden Blätter untersucht wurde, sondern nach dem ersten nur einige bestimmte mit entsprechender Differenz der Insertionshöhe und Größe herausgegriffen wurden, ist in den entsprechenden Tabellen durch einen vertikal abwärtszeigenden Pfeil in der ersten Vertikalkolumne angedeutet, der sich an $\mathrm{H}(1)$ anschließt. Ein leeres Feld bedeutet, daß eine zahlenmäßige Feststellung nicht erfolgte, ein horizontaler Strich, daß das betreffende Blatt der Pflanze fehlt. Die Daten über Spaltöffnungen beziehen sich auf $1 \mathrm{qmm}, \infty=\mathrm{sehr}$ viele, $\angle 1=$ sehr wenige. 
Tegment an aufwärts stetig größer wird, so daß das Minimum innerhalb der Schuppenregion liegen muß.

Die Resultate der Einzeluntersuchungen über die Veränderungen der Blattdicke innerhalb der Reihe der hochblattartigen Formen sind zum Teil in der Tabelle II wiedergegeben. Ein Blick auf diese Tabelle überzeugt uns davon, daß von der oberen Grenze der Laubblattregion

Tabelle II.

\begin{tabular}{|c|c|c|c|c|c|c|c|c|c|}
\hline & $\begin{array}{l}\text { Syringa } \\
\text { vulgaris }\end{array}$ & $\begin{array}{l}\text { Rhus } \\
\text { Cotinus }\end{array}$ & $\begin{array}{l}\text { Ligu- } \\
\text { strum } \\
\text { vulgare }\end{array}$ & $\begin{array}{l}\text { Weigelia } \\
\text { amabilis }\end{array}$ & $\begin{array}{l}\text { Hydran- } \\
\text { gea pani } \\
\text { culata }\end{array}$ & $\begin{array}{c}\text { Spiraea } \\
\text { Douglasii }\end{array}$ & $\begin{array}{c}\text { Sy- } \\
\text { ringa } \\
\text { Emodi }\end{array}$ & $\begin{array}{c}\text { Rubus } \\
\text { pli- } \\
\text { catus }\end{array}$ & $\begin{array}{l}\text { Rosa } \\
\text { (Kelch- } \\
\text { zipfel) }\end{array}$ \\
\hline $\begin{array}{l}\mathrm{L}(\mathrm{n}) \\
\mathrm{H}(1)\end{array}$ & $\begin{array}{l}250 \\
233\end{array}$ & 110 & 183 & $\begin{array}{l}285 \\
229\end{array}$ & 180 & $\begin{array}{r}157 \\
96\end{array}$ & 286 & 132 & $\begin{array}{l}164 \\
180\end{array}$ \\
\hline & $\begin{array}{l}167 \\
155\end{array}$ & 70 & 167 & $\begin{array}{l}168 \\
173 \\
157\end{array}$ & $\begin{array}{l}171 \\
138\end{array}$ & 71 & $\begin{array}{l}196 \\
182\end{array}$ & $\begin{array}{l}114 \\
107 \\
103\end{array}$ & $\begin{array}{l}138 \\
120\end{array}$ \\
\hline
\end{tabular}

an sproßaufwärts die Blätter allmählich dünner werden. Diese letzte Tatsache fand ich bei Kühlhorn bestätigt.

Unter Berücksichtigung der von Nordhausen (pag. 487) für die Laubblattregion der Sonnensprosse festgestellten Gesetzmäßigkeit ergibt sich somit für die Reihe sämtlicher chlorophyllgrüner und nicht tegmentartig modifizierter Blattgebilde und Laubblätter des Sprosses folgendes Bild: die Blattdicke steigt von einem Minimum innerhalb der Region der basalen Übergangsblätter gleichmäßig bis fast zum letzten Laubblatt ${ }^{1}$, um dann in der Reihe der Hochblattformen ebenso stetig wieder abzunehmen.

\section{Epidermis.}

Bekanntlich ist bei den Knospenschuppen die Außenwand der unteren Epidermis in verschiedenem Maße dicker als die gleichfalls etwas verdickte Außenwand der oberen Epidermis. Diese Dickendifferenz

1) Im Gegensatz zu dieser auch aus der Arbeit von Schramm zu entnehmenden Regel über die Blattdicke in der Laubblattzone behauptet Kühlhorn in einer Arbeit, die bisher übersehen worden ist, und die ich erst nachträglich kennen lernte, daß ,die Dicke der verschiedenen Laubblätter bei den einzelnen Objekten in der Regel nach oben hin abnimmt" (pag. 116). Dieser Satz stellt eine ganz unzulässige Verallgemeinerung dar, denn nach seinen Einzeluntersuchungen gilt er für die eigentlichen Laubblätter normaler Größe nur bei einem Drittel der untersuchten Pflanzen, und ist auch hier noch wegen der geringen Zahl der untersuchten Blätter durchaus unsicher. 
ist am größten und deutlichsten in der untersten Knospenschuppe und wird sproßaufwärts allmählich geringer, indem die Außenwand der Unterepidermis mehr an Dicke abnimmt als die der Oberepidermis; doch noch in den unteren Übergangsblättern macht sie sich fast stets bemerkbar, und erst die oberen weisen etwa gleich dicke Epidermisaußenwände auf (Chionanthus virginica, Forsythia suspensa, Diervillea sessilifolia, Salix pentandra, Spiraea Billiardi, Syringa vulgaris, Ilex integra, Lonicera Caprifolium, Ligustrum vulgare). Auch bezüglich der radialen Epidermi'swände läßt sich in den unteren Übergangsblättern häufiger (Chionanthus, Forsythia, Salix) eine solche Strukturähnlichkeit mit den Tegmenten beobachten, indem diese hier oft dicker als in den jüngeren Übergangsblättern und den Laubblättern sind.

Die Laubblätter können - im Gegensatz zu den oberen Übergangsblättern an der Sproßbasis - auf der Oberseite eine dickere Epidermisaußenwand aufweisen. Bei Ligustrum vulgare, wo dies beispielsweise der Fall ist, zeigen die Hochblattformen wieder gleich dicke Epidermisaußenwände. Bemerkenswerterweise besitzen die Spreitenteile, welche die Rose häufig an der Spitze ihrer Kelchzipfel ausbildet, viel stärker verdickte Epidermisaußenwände als ein gleich stark belichtetes Laubblatt aus der Nähe der Sproßspitze (Fig. 11). Bei den Hochblattformen der übrigen Pflanzen fand sich keine nennenswerte Verdickung der Epidermisaußenwände, während Kühlh orn (pag. 117) dies für die Hochblätter der von ihm untersuchten krautartigen Pflanzen allgemein angibt.

Unter den Veränderungen, welche die Größe der Epidermiszellen in den Blattreihen erfährt, beschäftigen uns zunächst diejenigen, die sie in der Dimension senkrecht zur Blattfläche zeigt, d. h. also die Veränderungen der im Querschnitt gemessenen Höhe. Diese wurden in der Region der Übergangsblätter an der Sproßbasis verfolgt bei Syringa vulgaris, Chionanthus virginica, Forsythia suspensa, Lonicera Caprifolium, Ligustrum vulgare, in der Region der Hochblattformen bei Syringa vulgaris, Rosa (Kelchspreiten), Hydrangea paniculata, Spiraea Douglasii, Weigelia amabilis, Rubus plicatus. Für einige Pflanzen sind die Daten in $\mu$ in der Tabelle III (pag. 164) zusammengestellt.

Beginnen wir auch hier bei den Tegmenten, so finden wir bei diesen die Verhältnisse insofern etwas außergewöhnlich, als wie schon erwähnt, die Epidermisaußenwände oft recht stark verdickt sind. Bei diesen Blattgebilden zog ich es vor, für die Epidermiszellen nur den radialen Durchmesser des Lumens, nicht die ganze Höhe einschließlich der Außenwand zu vergleichen. Dabei zeigte sich, daß in den Tegmenten die Zelllumina in der unteren Epidermis meist höher als in der oberen sind 
(Chionanthus, Syringa, Ligustrum), nur bei Forsythia sind beide Epidermen gleich hoch. Innerhalb der Reihe der Übergangsblätter gleichen sich dann die Unterschiede in der Höhe der Epidermis aus (Chionanthus, Syringa, Ligustrum), zum Teil wird sogar schon in diesen, zum Teil erst in den Laubblättern die Oberepidermis höher (Forsythia, Syringa, Ligustrum). Meist nehmen hierbei zugleich die Höhen der beiden Epidermen allmählich bis zum untersten Laubblatt hin zu (Forsythia, Syringa, Lonicera); nur bei Chionanthus ist sie in diesem etwas geringer als in den Tegmenten.

Tabelle III.

\begin{tabular}{|c|c|c|c|c|c|c|c|c|c|c|}
\hline & \multicolumn{2}{|c|}{$\begin{array}{l}\text { Syringa } \\
\text { vulgaris }\end{array}$} & \multicolumn{2}{|c|}{$\begin{array}{l}\text { Chionanthus } \\
\text { virginica }\end{array}$} & \multicolumn{2}{|c|}{$\begin{array}{c}\text { Forsythia } \\
\text { suspensa }\end{array}$} & \multicolumn{2}{|c|}{$\begin{array}{l}\text { Rosa (Kelch- } \\
\text { spreiten) }\end{array}$} & \multicolumn{2}{|c|}{$\begin{array}{l}\text { Weigelia } \\
\text { amabilis }\end{array}$} \\
\hline & $\mathrm{Oe}$ & $\mathrm{Ue}$ & $\mathrm{Oe}$ & $\mathrm{Ue}$ & $\mathrm{Oe}$ & Ue & $\mathrm{Oe}$ & $\mathrm{Ue}$ & $\mathrm{Oe}$ & $\mathrm{Ue}$ \\
\hline $\begin{array}{l}\mathrm{T} \\
\ddot{U}(1) \\
\ddot{U}(2) \\
\ddot{U}(3) \\
\ddot{U}(4) \\
\mathrm{L}(1) \\
\mathrm{H}(1)\end{array}$ & $\begin{array}{r}7 \\
18 \\
15 \\
15 \\
25\end{array}$ & $\begin{array}{l}16 \\
14 \\
15 \\
12 \\
16\end{array}$ & $\begin{array}{l}12 \\
12 \\
14 \\
12 \\
12\end{array}$ & $\begin{array}{l}17 \\
17 \\
14 \\
12 \\
\frac{12}{12}\end{array}$ & $\begin{array}{l}5 \\
17 \\
17,2 \\
24 \\
22 \\
22\end{array}$ & $\begin{array}{r}5 \\
10 \\
14 \\
17 \\
17 \\
17\end{array}$ & $\begin{array}{l}23 \\
23 \\
23 \\
20,5\end{array}$ & $\begin{array}{l}14 \\
14 \\
14 \\
17\end{array}$ & $\begin{array}{l}22 \\
23 \\
19 \\
17,5 \\
16,5\end{array}$ & $\begin{array}{l}16 \\
12,5 \\
13 \\
14 \\
14\end{array}$ \\
\hline
\end{tabular}

Die Hochblattformen zeigen bei allen Pflanzen (Weigelia, Spiraea Douglasii, Hydrangea, Ligustrum, Syringa vulgaris, Rhododendron, Rosa [Kelchzipfel]) mit Ausnahme von Rubus ein rückläufiges Verhalten; überall bei ihrem Verfolg sproßaufwärts zeigen sie die Tendenz, die Differenz der Epidermisdicken, die sich in den Laubblättern findet, allmählich wieder auszugleichen, meist indem die Oberepidermiszellen stetig etwas niedriger, die Unterepidermiszellen etwas höher werden. Dies ist um so deutlicher, je höher das Blatt inseriert ist, so daß schließlich die Zellen der unteren Epidermis denen der oberen in Größe und Form ähnlich sind, was auch Kühlhorn (pag. 118) bei den von ihm untersuchten Pflanzen beobachtete.

Nicht nur die im Querschnitt gemessene Höhe der Epidermiszellen, auch ihre in der Blattflächenansicht feststellbaren Größenmaße ändern sich oft innerhalb der Blattreihen. Verfolgt man die basalen Übergangsblätter von Syringa vulgaris und Lonicera sproßaufwärts, so läßt sich eine deutliche, stetig fortschreitende Größenzunahme der Epidermiszellen wahrnehmen, die bei Syringa so bedeutend ist, daß 
die Epidermiszellen eines tief inserierten Laubblattes etwa doppelt so groß wie die der untersten Knospenschuppe sind. Bei Chionanthus und Forsythia hingegen läßt sich eine Veränderung der Epidermiszellgröße in der Reihe der basalen Übergangsblätter nicht feststellen, jedenfalls nicht ohne Vornahme von Zählungen. Untersucht man diese Verhältnisse in der Zone der Hochblattformen, so findet man durchweg (Rhus, Ligustrum, Hydrangea, Spiraea Douglasii, Weigelia, Syringa Emodi, Rhododendron, Rubus), daß die Epidermiszellen beider Seiten mit wachsender Insertionshöhe der Blätter augenfällig kleiner werden.

Berücksichtigt man nun einerseits die Tatsache (Nordhausen, pag. 495), daß auch bei gut belichteten Sprossen, deren höher inserierte Blätter „Lichtblattcharakter" aufweisen, die ersten Blätter den Stempel des Schattenblattes tragen, und andererseits die Angabe Schramms (pag. 62), daß die Epidermiszellen der Schattenblätter erheblich größer als die der Lichtblätter sind, so gelangt man zu dem Ergebnis, daß innerhalb der aufwärts verfolgten Reihe aller Blattgebilde am Sproß, soweit sie nicht irgendwie tegmentartig modifiziert sind, die Epidermiszellen zunächst bis zur unteren Grenze der Laubblattzone entweder ungefähr gleich groß bleiben, oder allmählich an Größe zunehmen, daß sie dann von hier an sproßaufwärts bei allen Pflanzen stetig kleiner werden.

Weiterhin wurde auch den Änderungen, die die Form der Epidermiszellen in der Blattreihe eingeht, Beachtung geschenkt. Bei einigen Pflanzen (Chionanthus, Forsythia, Syringa vulgaris, Ligustrum) wurde in der Flächenansicht verfolgt, ob sich innerhalb der Blattreihen Länge und Breite der Epidermiszellen zueinander stets gleich verhalten. Es ergab sich, daß bei diesen Pflanzen die Epidermiszellen der mittleren und oberen Tegmente und der unteren Übergangsblätter immer mehr oder weniger deutlich längsgestreckt sind, während sie bei den obersten Übergangsblättern und bei den Laubblättern isodiametrisch sind. Beachtenswerterweise zeigen sich bei Syringa vulgaris und Ligustrum die Epidermiszellen der letzten Hochblätter dann wieder deutlich längsgestreckt (Fig. 6). Eine bestimmte Beziehung zur Blattform war nicht zu erkennen.

Hier möchte ich nebenbei auf eine Formverschiedenheit der unteren Epidermiszellen bei Syringa Emodi aufmerksam machen: die auf der Unterseite durch Hervorwölben der Epidermiszellen nach außen gebildeten Papillen sind beim Hochblatt sehr viel niedriger als beim Laubblatt. 
Mit besonderer Aufmerksamkeit wurde verfolgt, in welchem Sinne sich der oft wellenförmige oder zackige, oft glatte Verlauf der vonder Blattfläche gesehenen radialen Epidermiswände innerhalb der Blattreihen ändert. Gehen wir auch hier wieder von den Tegmenten aus, so sehen wir bei diesen fast stets die radialen Epidermiswände glatt verlaufen (Chionanthus, Forsythia, Salix pentandra ${ }^{1}$ ), Spiraea Billiardi, Syringa vulgaris, Ligustrum). Nur bei Diervillea zeigen die radialen Epidermiswände bereits in den letzten Tegmenten schwache Wellung. Bei mehreren Pflanzen (Chionanthus, Forsythia, Spiraea Billiardi) verlaufen sie auch noch in den unteren Übergangsblättern glatt, während sie bei anderen Arten (Diervillea, Syringa, Ligustrum) in diesen bereits mehr oder weniger deutlich einen wellen-
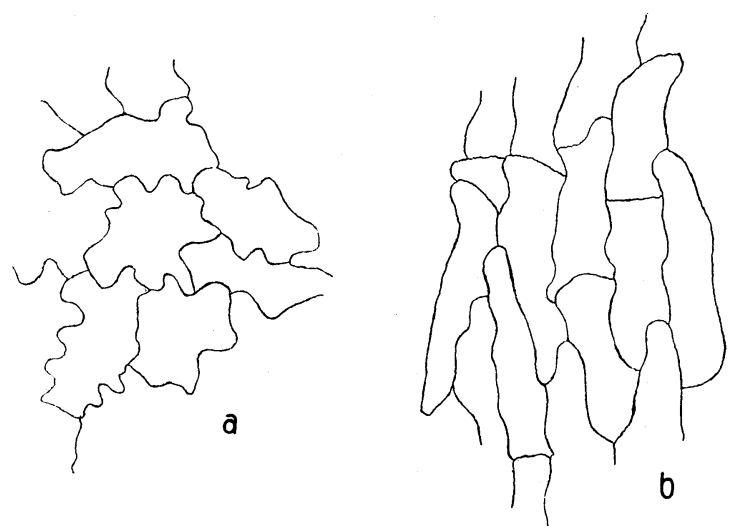

Fig. 6. Syringa vulgaris. Obere Epidermis in der Blattflächenansièht. a vorletztes, b letztes Hochblatt. Vergr. $490 / 1$.

förmigen Verlauf erkennen lassen. Bei allen in dieser Hinsicht untersuchten Pflanzen (Chionanthus, Ligustrum, Forsythia, Diervillea, Spiraea Billiardi, Syringa vulgaris, s. indessen die Anmerkung) weisen die obersten Übergangsblätter wenigstens in der unteren Epidermis deutlich wellenförmig verlaufende Radialwände auf. Bemerkenswert ist, daß bei Ligustrum die Radialwände der Oberepidermis bereits etwa im mittleren Übergangsblatt den höchsten Grad der Wellung erreichen, und das oberste Übergangsblatt dies Merkmal nur noch wenig zeigt. Ein Vergleich mit den Laubblättern, speziell mit den untersten ergibt, daß diese nie nennenswert stärkere Wellung aufweisen als das oberste Übergangsblatt $\left.^{2}\right)$.

1) Salix pentandra zeigt übrigens auch bei allen übrigen Blattformen keine Wellung.

2) Bezüglich Weigelia amabilis Carr. möchte ich noch folgende Tatsache mitteilen. Die Pflanze blüht, wie bekannt ist, zweimal während einer Vegetationsperiode; beim erstenmal werden Blüten am Ende kurzer, beim zweitenmal am Ende langer Triebe hervorgebracht. Die letzten Laubblätter solcher Kurztriebe verhalten 
Recht verschiedenartig verhalten sich die einzelnen Pflanzen in bezug auf die Epidermiswellung der Hochblattformen. Bei Neillia opulifolia, Weigelia amabilis, Ligustrum und Syringa vulgaris sind deren radiale Epidermiswände in verschiedenem Maße stärker gewellt als die der obersten Laubblätter, und zwar ist die Wellung um so deutlicher, je höher das Hochblatt inseriert ist; das gleiche gilt für die relativ großen Kelchblätter von Mespilus germanica, die sich, wie erwähnt, der Größe nach in die Blattstellungsschraubenlinie einordnen. Bei Syringa vulgaris nimmt dann in dem sehr kleinen obersten Deckblättchen, das anatomisch nur wenig differenziert und offenbar verkümmert ist, die Wellung wieder ab (Fig. 6). Im Gegensatz zu diesen Pflanzen ist bei den Hochblättern von Rhus Cotinus und Spiraea Billiardi, bei den Kelchspreiten von Rosa und bei den pag. 160 erwähnten Blattgebilden von Rhododendron praecox kein Unterschied der Wellung gegenüber dem obersten Laubblatt bemerkbar, und bei Spiraea Douglasii, Hydrangea und Rubus ist sie in den Hochblattformen eher etwas geringer als in den obersten Laubblättern.

Zieht man die Resultate von Schramm (pag. 62) und Nordhausen (pag. 495) hinzu, so gewinnt man folgendes Bild: die stets erst oberhalb der Tegmentregion auftretende Epidermiswellung nimmt beim Verfolg der basalen Übergangsblätter sproßaufwärts rasch zu und weist in der Grenzregion derselben gegen die Laubblätter, eventuell auch bereits früher, ein Maximum auf, sinkt darauf gleichmäBig bis zur oberen Grenze der Laubblattregion, um hier meist ganz zu schwinden; siekanndann in der Reihe der Hochblattformen wieder auftreten und erheblich zunehmen, und eventuell schließlich infolge Verkümmerung des Blattes wieder verschwinden.

Bei der Feststellung dieser Tatsachen bestätigte sich übrigens gleichzeitig die bereits bekannte Eigentümlichkeit, daß im allgemeinen die untere Epidermis mehr als die obere dazu neigt, ihre radialen Wände

sich nun bezüglich der Wellung der radialen Epidermiswände wie die tiefer inserierten der langen Triebe: die Radialwände der Oberepidermis sind glatt bis schwach gewellt, die der Unterepidermis stark zackig gewellt, wohingegen die letzten Laubblätter eines langen Triebes beiderseits glatte radiale Epidermiswände aufweisen. Bei dieser Pflanze stellen also die Kurztriebe offenbar die Basalstücke der Langtriebe dar, ein Verhalten, wie es bereits Nordhausen (pag. 490) an mehreren Pflanzen, insbesondere an Fagus silvatica, nachgewiesen hat. 
wellenförmig auszubilden. Schließlich möchte ich noch die Tatsache erwähnen, daß die Wellung in dem Blatt, in dem sie in der aufwärts verfolgten basalen Blattreihe zuerst auftritt, nicht immer in allen Spreitenteilen zugleich schon vorkommt; sie kann vielmehr zunächst nur in der Spitzenregion (Forsythia, Diervillea) oder nur in der mittleren Blattregion (Spiraea Billardi, Ligustrum) sich vorfinden; inwieweit hier entwicklungsgeschichtliche Vorgänge eventuell mitspielen, habe ich nicht verfolgt.

\section{Behaarung.}

Die Anzahl der auf die Flächeneinheit des Blattes fallenden eigentlichen Haare oder Drüsenhaare, die für die Tegmente und basalen UỦbergangsblätter an Ligustrum, Syringa vulgaris, Forsythia, Spiraea Billiardi, für die Hochblattformen an Weigelia amabilis Carr., Syringa vulgaris, Syringa Emodi, Spiraea Douglasii, Spiraea Billiardi, Rubus plicatus und Rhododendron praecox festgestellt wurde, zeigte innerhalb dieser Reihen bestimmte regelmäßige Veränderungen, und zwar ergab sich bei einem Vergleich der Blätter ausnahmslos folgendes: Haare fanden sich auf den unteren Tegmenten meist nur wenig, auf der im Winter unbedeckten Fläche ihrer Unterseite fehlten sie fast immer. Mit der Insertionshöhe der Blätter nahm die Zahl der Haare zunächst zu, bis innerhalb der Reihe der basalen Übergangsblätter das Maximum der Behaarung auftrat; darüber hinaus nahm sie bis zur Region der Laubblätter hin wieder ab.

Für die Zone der Hochblattformen ist es charakteristisch, daß die Haare erheblich dichter als bei den Laubblättern stehen, und zwar um so mehr, je höher das Hochblatt inseriert ist; beispielsweise trägt bei Spiraea Douglasii das Laubblatt auf der Oberseite pro Quadratmillimeter 15, das erste Hochblatt 115 Haare, und bei Rubus plicatus ist die Zahl der oberseits auftretenden langen, einfachen Haare, auf die Flächeneinheit bezogen, auf dem ersten Hochblatt 24 mal so groß wie auf dem Endfieder eines hoch inserierten Laubblattes. Zur Veranschaulichung des beschriebenen regelmäßigen Verhaltens führe ich noch als Beispiel für zwei Pflanzen die längs desselben Sprosses verfolgte Änderung der Blattbehaarung zahlenmäßig vor: bei Spiraea Billiardi beträgt die Zahl der oberseitigen einfachen Haare pro Quadratmillimeter bei den einzelnen Blättern $\ddot{U}(2) 4, \ddot{U}(3) 45, \ddot{U}(4) 80, \ddot{U}(5) 30, L(1) 17, H(1) 82$; bei Syringa vulgaris finden sich auf beiden Blattseiten Kolleteren, ihre Menge pro Quadratmillimeter ist bei den einzelnen Blättern T(1) 0, T(2) 123, T(3) 216, $\mathrm{T}(4) 210, \ddot{\mathrm{U}}(1) 325, \ddot{\mathrm{U}}(2) 138, \ddot{\mathrm{U}}(3)$ 148, H(1) 37, H(2) 51, H(3) 64. Hierbei ist darauf hinzuweisen, daß, wie bereits angeführt ist, die Zahl der Epidermiszellen pro Flächeneinheit von den unteren Tegmenten bis zu den 
Laubblättern entweder gleich bleibt oder mit der Insertionshöhe konstant abnimmt, und daß innerhalb der Reihe der Hochblattformen ihre Zahl in weit geringerem Maße zunimmt als die Zahl der Haare. Eine Korrelation zwischen der Zahl der Haare und der Zahl der Epidermiszellen besteht somit nicht.

Durch Kombination mit den Angaben von Yapp und Nordhausen (pag. 494) kommt man zu folgendem Gesamtbild: die Zahl der Haare ist auf den Tegmenten gering, steigt innerhalb der Region der basalen Übergangsblätter rasch zu einem Höchstwert, $\cdot u m$ weiter zur Laubblattregion hin fast ebenso rasch wieder zu sinken, und nimmt dann sproßaufwärts innerhalb derselben und innerhalb der Reihe der Hochblattformen fortwährend wieder zu.

\section{Spaltöffnungen.}

Die Verteilung der die Ausführgänge des Interzellularsystems darstellenden Spaltöffnungen wurde sowohl bei den Blättern der basalen Übergangszone (Syringa vulgaris, Lonicera Caprifolium, Chionanthus viriginica,. Forsythia suspensa, Diervillea sessilifolia, Salix pentandra, Spiraea Billiardi, Ligustrum vulgare) als auch bei den Hochblattformen (Spiraea Billiardi, Ligustrum vulgare, Hydrangea paniculata, Spiraea Douglasii, Syringa Emodi, Weigelia amabilis, Rhus Cotinus, Syringa vulgaris, Rubus plicatus, ferner bei den Kelchspreiten von Rosa und Mespilus germanica) besonders beachtet. Wir beginnen auch hier bei den Knospenschuppen und finden, daß die einzelnen Pflanzen sich hinsichtlich der Verteilung der Spaltöffnungen auf ihnen recht verschieden verhalten: bei Salix pentandra fehlen sie ganz, bei Syringa vulgaris $^{1}$ ) und Ligustrum liegen sie nur auf der Oberseite, bei Rhus und Chionanthus nur auf der Unterseite, und schließlich bei Forsythia, Diervillea, Spiraea Billiardi und Lonicera auf beiden Seiten der Tegmente.

Verfolgt man nun weiter aufwärts in der Reihe der basalen Übergangsblätter zunächst die Verteilung der oberseitigen Spaltöffnungen, soweit solche auftreten, so ergibt sich eine bestimmte Regelmäßigkeit: in allen Fällen nämlich (Syringa vulgaris, Ligustrum, Forsythia, Spiraea Billiardi, Lonicera, Salix pentandra), mit Ausnahme

1) Bei dieser Pflanze fand sich auf der Oberseite der älteren Knospenschuppen merkwürdigerweise ein Teil der Spaltöffnungen deutlich über die Blattoberfläche emporgehoben; das gleiche beobachtete ich auf der Unterseite der Tegmente von Ribes sanguineum. 
von Diervillea, wächst die Zahl derselben zunächst mit der Insertionshöhe der Blattgebilde, erreicht innerhalb der Reihe der Übergangsformen den höchsten Wert und fällt beim weiteren Verfolg dieser Blätter sproßaufwärts wieder (s. Tabelle IV). Im Gegensatz zu den Übergangsblättern an der Sproßbasis weisen meist die Laubblätter dann niemals oberseitige Spaltöffnungen mehr auf (Diervillea, Salix pentandra, Spiraea Billiardi, Ligustrum, Lonicera), oder doch nur sehr spärlich (Forsythia), oder zerstreuter (Syringa vulgaris). - Eine flüchtige Orientierung an einigen anderen Gartensträuchern mit spreitenartigen Tegmenten ergab übrigens, daß unter anderem auch Jasminum nudiflorum, Exochorda und Syringa chinensis auf den Übergangsblättern an der Sproßbasis oberseitige Spaltöffnungen aufweisen.

Tabelle IV ${ }^{1}$ ).

\begin{tabular}{|c|c|c|c|c|c|c|c|c|c|c|c|c|}
\hline & \multicolumn{2}{|c|}{$\begin{array}{l}\text { Chionan- } \\
\text { thus } \\
\text { virginica }\end{array}$} & \multicolumn{2}{|c|}{$\begin{array}{c}\text { Salix } \\
\text { pentandra }\end{array}$} & \multicolumn{2}{|c|}{$\begin{array}{l}\text { Forsythia } \\
\text { suspensa }\end{array}$} & \multicolumn{2}{|c|}{$\begin{array}{c}\text { Spiraea } \\
\text { Billiardi }\end{array}$} & \multicolumn{2}{|c|}{$\begin{array}{l}\text { Syringa } \\
\text { vulgaris }\end{array}$} & \multicolumn{2}{|c|}{$\begin{array}{c}\text { Ligustrum } \\
\text { vulgare }\end{array}$} \\
\hline & $\mathrm{Oe}$ & $\mathrm{Ue}$ & $\mathrm{Oe}$ & $\mathrm{Ue}$ & $\mathrm{Oe}$ & $\mathrm{Ue}$ & $\mathrm{Oe}$ & $\mathrm{Ue}$ & $\mathrm{Oe}$ & $\mathrm{Ue}$ & $\mathrm{Oe}$ & $\mathrm{Ue}$ \\
\hline & 0 & 1 & 0 & 0 & 15 & $<1$ & $<1$ & $<1$ & $|34| 22$ & 0 & $0 \mid 27$ & $0 \mid 0$ \\
\hline $\mathbf{U}(1$ & 0 & 32 & 18 & 2 & 49 & 15 & $61 \mid 33$ & $75 \mid 92$ & \begin{tabular}{l|l|l} 
& 11 & 23
\end{tabular} & $0 \mid 9$ & $72 \mid 3$ & $30 \mid 75$ \\
\hline Ü (2) & 0 & 34 & 33 & 38 & 45 & 15 & 90 & 112 & 46 & $40 \mid 81$ & $58 \mid 0$ & $\infty$ \\
\hline$\ddot{U}$ & 0 & 65 & - & - & 13 & $\begin{array}{l}15 \\
47\end{array}$ & 41 & $\infty$ & 45 & 94 & - & - \\
\hline$\ddot{\mathrm{U}}$ & - & - & - & - & 19 & $\begin{array}{r}47 \\
125\end{array}$ & 27 & $\infty$ & - & - & - & - \\
\hline $\mathrm{L}$ & 0 & 120 & 0 & $\infty$ & 4 & 19 & 0 & $\infty$ & 37 & 360 & 0 & 158 \\
\hline
\end{tabular}

Bemerkenswerterweise treten bei mehreren Pflanzen, auf deren Laubblättern oberseitige Spaltöffnungen vollständig fehlen, solche a uf den Hochblattformen dann wieder auf (Spiraea Billiardi, Spiraea Douglasii, Ligustrum, Weigelia, ferner Rosa und Mespilus [Kelchspreiten]), oder sie sind auf den Hochblättern in größerer Zahl vorhanden, wenn sie auf dem Laubblatt nur recht spärlich (Neillia) oder zerstreut (Syringa vulgaris) vorkommen (s. Tabelle V, pag. 171).

Beachten wir jetzt die unterseitigen Spaltöffnungen, und zwar vorerst auf den Blättern an der Sproßbasis, so sehen wir zunächst, daß

1) Stehen in einem Felde zwei durch vertikalen Strich getrennte Zahlen, so bezieht sich die erste auf die apikale, die zweite auf die basale Blatthälfte. Espe hat in seiner Arbeit (Beiträge zur Kenntnis der Verteilung der Spaltöffnungen über die Blattspreite) die Verteilung der Spaltöffnungen auf den basalen Übergangsblättern nur bei Syringa vulgaris verfolgt; im Prinzip decken sich meine diesbezüglichen Angaben mit den seinen. 
Tabelle V.

\begin{tabular}{|c|c|c|c|c|c|c|c|c|c|c|c|c|c|c|}
\hline & \multicolumn{2}{|c|}{$\begin{array}{l}\text { Weigelia } \\
\text { amabilis }\end{array}$} & \multicolumn{2}{|c|}{$\begin{array}{l}\text { Syringa } \\
\text { vulgaris }\end{array}$} & \multicolumn{2}{|c|}{$\begin{array}{c}\text { Rhus' } \\
\text { Cotinus }\end{array}$} & \multicolumn{2}{|c|}{$\begin{array}{l}\text { Mespilus } \\
\text { (Kelch- } \\
\text { spreiten) }\end{array}$} & \multicolumn{2}{|c|}{$\begin{array}{l}\text { Hydrangea } \\
\text { paniculata }\end{array}$} & \multicolumn{2}{|c|}{$\begin{array}{c}\text { Ligustrum } \\
\text { vulgare }\end{array}$} & \multicolumn{2}{|c|}{$\begin{array}{l}\text { Neillia } \\
\text { opulifolia }\end{array}$} \\
\hline & $\mathrm{Oe}$ & $\mathrm{Ue}$ & Oe & $\mathrm{Ue}$ & $\mathrm{Oe}$ & $\mathrm{Ue}$ & $\mathrm{Oe}$ & $\mathrm{Ue}$ & $\mathrm{Oe}$ & $\mathrm{Ue}$ & $\mathrm{Oe}$ & $\mathrm{Ue}$ & $\mathrm{Oe}$ & $\mathrm{Ue}$ \\
\hline $\begin{array}{l}\mathrm{I} \\
\mathrm{H}(1)\end{array}$ & $\begin{array}{r}0 \\
0 \\
4 \\
10 \\
33\end{array}$ & $\begin{array}{l}\infty \\
\infty \\
97 \\
61 \\
44\end{array}$ & $\begin{array}{l}37 \\
39 \\
47 \\
42 \\
-\end{array}$ & $\begin{array}{r}306 \\
116 \\
64 \\
31 \\
\end{array}$ & 0 & $\begin{array}{r}150 \\
55\end{array}$ & $\begin{array}{l}0 \\
1 \\
8\end{array}$ & & 0 & 112 & 12 & $\begin{array}{l}158 \\
101\end{array}$ & $\begin{array}{r}<1 \\
45\end{array}$ & \\
\hline
\end{tabular}

sie in den Fällen, wo sie auf den Tegmenten fehlen (Salix pentandra, Syringa vulgaris, Ligustrum), etwa auf den ersten Übergangsblättern zuerst auftreten.

Beim Verfolg der basalen Übergangsblätter sproßaufwärts finden wir dann hinsichtlich der Veränderung ihrer Zahl eine bestimmte Regelmäßigkeit, doch von ganz anderem Sinne wie die für die oberseitigen Spaltöffnungen aufgefundene: stets nimmt ihre Zahl vom untersten Tegment bis zur Laubblattregion hin mit der Insertionshöhe zu (s. Tabelle IV, pag. 170). In der Region der Hochblattformen ist das Verhalten umgekehrt: mit steigender Insertionshöhe der Blätter sinkt die Zahl der unterseitigen Spaltöffnungen, trotzdem die der Epidermiszellen zunimmt. Dieselbe Regel offenbart sich nun auch bezüglich der Summe der Spaltöffnungen beider Blattseiten: sie nimmt sproßaufwärts in der Region der basalen Übergangsblätter stetig zu, in der der Hochblattformen stetig ab.

Unter Zuhilfenahme der Angaben von Yapp und Schramm (pag. 63) wird man sich von der Verteilung der unterseitigen Spaltöffnungen über die Gesamtreihe der laubblattförmigen Gebilde am Sproß folgendes Bild konstruieren: ihre Zahl nimmt innerhalb der Reihe der basalen Übergangsblätter und derLaubblätter stetig zu, erreicht das Maximum bei den letzten Laubblättern und sinkt beim weiteren Verfolg sproßaufwärts in der Reihe der Hochblattformen wieder; dieselbe Regel gilt infolge der relativ geringen Anzahl der oberseitigen Spaltöffnungen auch für die Gesamtmenge der auf die Flächeneinheit des zweiseitigen Blattes fallenden Spaltöffnungen.

Auf die Verteilung der Spaltöffnungen über ein-und dieselbe Spreite wurde bei den basalen Übergangsblättern von Diervillea, Lonicera, Spiraea Billiardi, Ligustrum, Syringa vulgaris geachtet. Es 
ergab sich durchweg, daß auf der Blattoberseite die Zahl der Spaltöffnungen stets in der Spitzenhälfte größer als in der Basishälfte ist, auf der Blattunterseite hingegen stets in der Basishälfte größer als in der Spitzenhälfte. Es entspricht also der Spitzenteil als der entwicklungsgeschichtlich wahrscheinlich ältere in seiner Struktur einem tiefer inserierten Blatte.

Ich bemerke übrigens noch, daß im Dunkeln ausgetriebene Knospen an Laubsprossen von Salix pentandra, Lonicera und Syringa vulgaris in Bezug auf die Anordnung der Spaltöffnungen insbesondere auf der Oberseite annähernd gleiche Verhältnisse wie die entsprechenden Blattgebilde normaler Lichtsprosse zeigen, und ferner daß die Spaltöffnungen der Übergangsblätter von Syringa vulgaris bereits in der geschlossenen Knospe angelegt sind. Auch die Schuppenblättchen, die sich an den aus dem Boden hervorbrechenden Ausläufersprossen der letzterwähnten Pflanze unterhalb der Bodenoberfläche finden, zeigen etwa ebensoviele oberseitige Spaltöffnungen wie die entsprechenden Blätter normaler Lichtsprosse.

\section{Mesophyll.}

Auch unsere Betrachtung. des Mesophylls setzt naturgemäß bei den Knospenschuppen derjenigen Pflanzen ein, deren basale Übergangsblätter Gegenstand der Untersuchung waren (Chionanthus virginica, Forsythia suspensa, Diervillea sessilifolia, Salix pentandra, Spiraea Billiardi, Syringa vulgaris, Lonicera Caprifolium, Ilex integra, Rhus Cotinus, Ligustrum vulgare). An den Tegmenten fällt sogleich in die Augen, daß die Zahl der Mesophyllschichten in der Mediane meist viel höher als in der Mitte einer Blatthälfte ist, und ferner, daß sie nur wenig Chlorophyll enthalten. Weiterhin zeigen in verschiedenen Höhen ausgeführte Schnitte, daß die untere Partie eines Tegments gegenüber der oberen entsprechend seiner Entwicklungsgeschichte stets einen mehr fortgeschrittenen, dem der höher stehenden Blattgebilde ähnlichen Bautypus aufweist. Zwischen den Mesophyllzellen eines Tegmentes bestehen, abgesehen von bestimmten weiter unten erörterten Fällen, keine wesentlichen Unterschiede hinsichtlich Form, Größe und Fügung. Oft sind die Zellen dicht, $d$. h. völlig oder fast ohne Interzellularen gefügt, dann sind gleichzeitig auch die Wände mehr oder weniger verdickt (Forsythia, Salix, Ligustrum, ferner Syringa und Ilex in den unteren Tegmenten). Oder die Mesophyllzellen haben mehr oder weniger abgerundete Form, so daß an den Stellen, wo mehr als zwei Zellen aneinander stoßen, kleine Eckinterzellularen liegen, zugleich sind dann meist die Wände wenig verdickt (Chionanthus, Diervillea, Lonicera, Rhus, ferner Syringa vulgaris 
und Ilex in den oberen Tegmenten). Nebenbei sei erwähnt, daß in vielen Tegmenten (Syringa, Ligustrum, Diervillea, Lonicera, Salix, Chionanthus) parallel zur Blattfläche, meist in den oberen Schichten, lysigene, luftführende Spalte auftreten, die oft mit Kristalldrusen angefüllt sind ${ }^{1}$ ).

In einigen Fällen machen sich deutliche und beachtenswerte Unterschiede zwischen Ober- (Innen-) und Unter(Außen-)seite bemerkbar, die das Tegment in mancher Hinsicht umgekehrt wie das Laubblatt gebaut erscheinen lassen. So sind in den letzten Tegmenten von Diervillea, Syringa und Lonicera die obersten Schichten erheblich lockerer gebaut als die unteren, sie tragen sogar bei Syringa infolge des Auftretens von spaltenförmigen Interzellularen zwischen den Grenzflächen je zweier aneinanderstoßender Zellen das Bild eines primitiven Schwammparenchyms. Hiermit steht übrigens ohne Zweifel auch die oberseitige Anordnung der Spaltöffnungen als Ausgängen des Interzellularsystems in Zusammenhang. Weiterhin sind bei einigen Pflanzen (Ligustrum, Chionanthus, ferner Syringa in den unteren Tegmenten) die Zellen der obersten Mesophyllschichten parallel zur Blattfläche mehr oder weniger abgeplattet und kleiner als die übrigen. Ein Unterschied beider Blattseiten hinsichtlich des Chlorophyllgehalts läßt sich bei Rhus, Lonicera, Spiraea und Diervillea beobachten: die unteren Schichten sind hier merklich reicher an Chlorophyll als die oberen.

In einigen Fällen waren die Zellen der untersten, also äußersten Mesophyllschicht palisadenartig gestreckt; bei Rhus und Chionanthus zeigten sie diese Streckung senkrecht zur Blattfläche nur stellenweise und unvollkommen, deutlich bei Syringa und Ilex. Bei Syringa fanden sich diese unterseits auftretenden palisadenförmigen Zellen in der oberen Partie des letzten Tegmentpaares, und zwar betrug das Verhältnis Länge zu Breite bei ihnen durchschnittlich 1,7; bei Ilex war in allen Tegmenten die unterste, in den älteren Tegmenten sogar auch die zweitunterste Mesophyllschicht in dieser Weise ausgebildet. Erwähnenswert ist, daß auch bei einer nach den Blattmerkmalen wahrscheinlich als Salix fragilis anzusprechenden Weidenart jene

1) Bei Syringa vulgaris findet sich auf der Unter-(Außen-)seite der ältesten Schuppe öfters Periderm, dessen Bildung stets von der untersten Mesophyllschicht ausgeht. An solchen Stellen ist bzw. wird die allgemein stark verdickte Epidermisaußenwand dünner, zugleich sind in den Epidermiszellen die Sekrettröpfchen zahlreicher und größer und geben zum Teil andere Reaktion wie sonst. Ob es sich bei allen diesen Erscheinungen um die Folgen einer normalen physiologischen Reaktion oder um einen Zersetzungsprozeß durch Mikroorganismen handelt, ist ungewiß. 
unterseitigen palisadenförmigen Zellen vorkamen, und zwar in den schuppenartigen Vorblättern von Sprossen, die aus der Achsel von Blättern der gleichen Vegetationsperiode entsprangen. Allerdings waren diese palisadenartig gestreckten Zellen bei den letzten drei Pflanzen (Syringa, Ilex, Salix) relativ chlorophyllarm, sie standen vollkommen dicht und erschienen von der Blattfläche gesehen polygonal. Derartige Zellen hat auch Adlerz wahrscheinlich vor Augen bei der Angabe (nach dem Referat des schwedischen Originals in Just's Jahresberichten 1883, Bd. II, pag. 524), daß, wenn es zur Ausbildung von Palisadenzellen komme, diese immer auf der äußeren Seite der Knospenschuppen auftreten. Übrigens fand ich anderswo nirgends Angaben über das Vorkommen von Palisaden in Tegmenten, C. G. R. Schumann führt später sogar als negatives Charakteristikum der Knospenschuppen an, daß in ihnen nirgends Palisadenparenchym zu finden sei. Diese Unsicherheit ist vielleicht darauf zurückzuführen, daß für gewöhnlich nur die äußeren Tegmente berücksichtigt werden, während wir es hier mit jüngeren zu tun haben, die fast schon zu den Übergangsblättern gehören.

In der Reihe der Übergangsblätter an der Sproßbasis nimmt mit der Insertionshöhe der Chlorophyllgehalt dieser Blätter allmählich zu, gleichzeitig verschwindet nach und nach sowohl der Unterschied in der Blattdicke zwischen Mitte und Rand, der sich bei fast jedem Tegment konstatieren läßt, als auch der ebenfalls für die Tegmente charakteristische Unterschied zwischen der Struktur der apikalen und basalen Blatthälfte.

Wenn wir die Übergangsblätter von den Tegmenten an aufwärts verfolgen, sehen wir das Gefüge des gleichartigen Mesophylls (Fig. 10 b) sich zunächst lockern, indem die Interzellularen größer und reichlicher werden (Ligustrum, Syringa, Spiraea, Salix, Forsythia, Chionanthus), (s. Fig. 7), ganz besonders da, wo in den Tegmenten die Zellen sehr dicht gefügt waren; gleichzeitig werden die Wände dünner. Bald tritt dann ein Blatt auf, in welchem, oft nur im entwicklungsgeschichtlich jüngeren basalen Teil, die regelmäßig angeordneten Zellen der obersten Mesophyllschicht stellenweise senkrecht zur Außenfläche etwas gestreckt erscheinen (Fig. 10 c). Hier manifestiert sich also zum ersten Male der beim Laubblatt so scharf ausgeprägte dorsiventrale Bau des Mesophylls. In der Oberflächenansicht sind die gleichen Zellen entweder noch unregelmäßig polygonal und wenig abgerundet (Chionanthus, Salix, Lonicera) oder schon rund und relativ locker angeordnet (Ligustrum, Syringa, Forsythia; Fig. 7c), stets aber noch ziemlich groß. Die übrigen Schichten desselben Blattes haben Zellen von abgerundeter, unregelmäßiger, selten abge- 
flachter Form mit vielen kleinen Interzellularen. Das Chlorophyll ist - meist in den oberen Schichten reichlicher.

In den folgenden Übergangsblättern sind dann die Zellen der obersten Mesophyllschicht alle deutlich palisadenartig gestreckt (s. Fig. $10 \mathrm{~d}$ ) und in der Oberflächenansicht stets rund (Fig. $7 \mathrm{~d}$ ). Sie sind um so stärker gestreckt, je höher das Blatt steht, ja, oft sind sie in den oberen Übergangsblättern schon quergeteilt, oder es sind auch die Zellen der zweiten Schicht bereits palisadenartig ausgebildet. Zugleich wird von Blatt zu Blatt die Dicke der Palisadenzellen geringer und ihr Gefüge stetig dichter (Fig. 7, c-e); nur bei Lonicera und Chionanthus erweitern
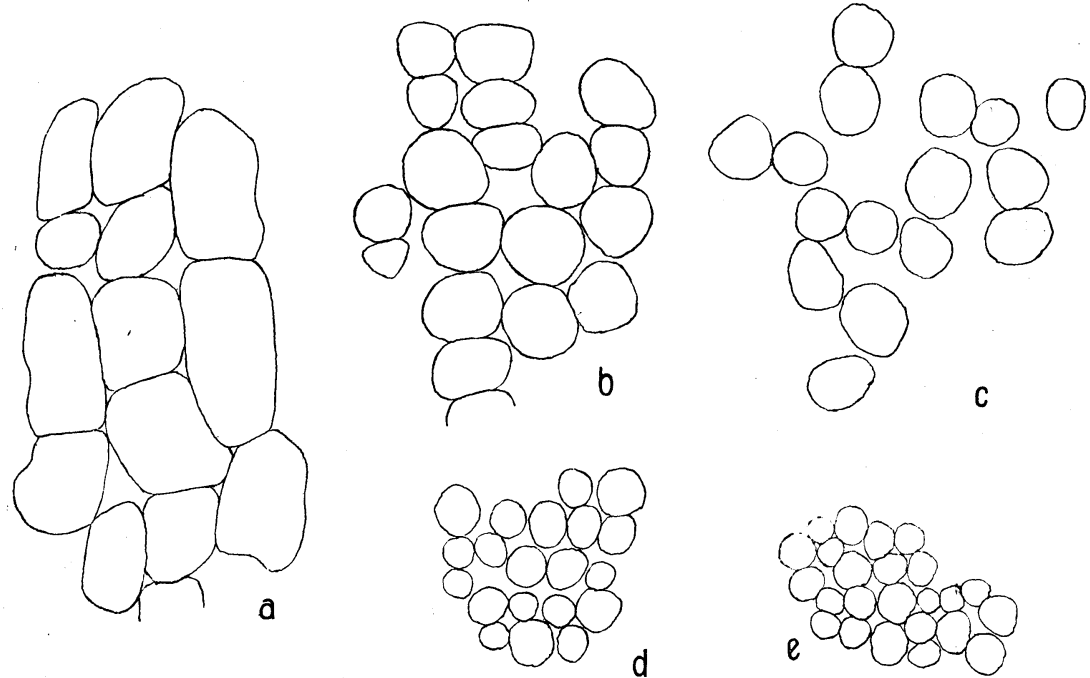

Fig. 7. Forsythia suspensa. Zellen der obersten Mesophyllschicht, von der Blattfläche gesehen. a 1. Übergangsblatt, b 2. Übergangsblatt, c 3. Übergangsblatt, d 4. Übergangsblatt, e 1. Laubblatt. Bei c, d und e sind die Zellen im Querschnitt palisadenartig gestreckt. Vergr. $490 / 1$.

sich sproßaufwärts zunächst die Zwischenräume der Palisaden noch etwas, schließlich aber rücken diese auch hier mehr und mehr zusammen. Die übrigen Schichten zeigen immer mehr den typischen Charakter des Schwammparenchyms: die Zellen flachen sich ab, tragen kürzere oder längere Armfortsätze und sind um so lakunöser, je höher das Blatt inseriert ist. Stets sind die Palisaden reicher an Chlorophyll.

Nach dem Vorgange anderer Autoren (s. Schramm, pag. 13) läßt sich das als Mesophyllquotient bezeichnete Verhältnis

Dicke des Palisadenparenchyms

Dicke des Schwammparenchyms 
recht gut als Charakteristikum der Blattstruktur verwenden. Es zeigt sich dann (s. Tabelle VI, in welcher die Dicke jener Gewebe in $\mu$ angegeben ist), daß innerhalb der Reihe der Übergangsblätter der Mesophyllquotient nach oben zu stetig wächst, meist weil die Dicke des Palisadengewebes mehr zunimmt als die des Schwammparenchyms.

Tabelle VI.

\begin{tabular}{|c|c|c|c|c|c|c|c|c|c|}
\hline & \multicolumn{3}{|c|}{ Chionanthus virginica } & \multicolumn{3}{|c|}{ Forsythia suspensa } & \multicolumn{3}{|c|}{ Syringa vulgaris } \\
\hline & 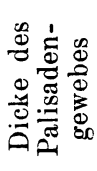 & 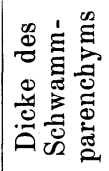 & 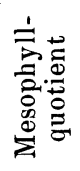 & 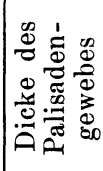 & 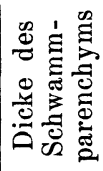 & 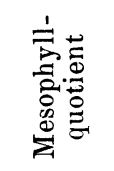 & 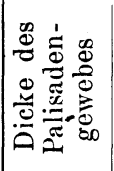 & 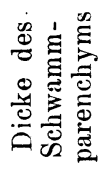 & 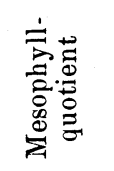 \\
\hline$\ddot{\mathrm{U}}(1)$ & 0 & 0 & 0 & 0 & 0 & 0 & 0 & 0 & 0 \\
\hline$\ddot{U}(2)$ & 0 & 0 & 0 & 0 & 0 & 0 & 50 & $1+2$ & $0,3-0,5$ \\
\hline$\ddot{U ̈ ~(3) ~}$ & 25 & 51 & 0,5 & 51 & 117 & $0,4-0,5$ & 64 & $7 !)$ & $0,7-0,9$ \\
\hline$\ddot{U}(4)$ & - & - & - & 80 & 125 & $0.5-0.6$ & - & - & - \\
\hline $\mathrm{L}(1)$ & 35 & 58 & 0,6 & 72 & 138 & $0, \overline{0}-0.6$ & $\left.1: 30^{1}\right)$ & $\left.67^{\prime}\right)$ & $\left.1,9^{1}\right)$ \\
\hline
\end{tabular}

Erwähnenswert ist noch, daß die früher erwähnten Luftspalten mit zunehmender Insertionshöhe in den basalen Übergangsblättern kleiner und seltener werden und allmählich verschwinden (Fig. 10). Überall, wo Kristalldrusen auftreten (Rhus, Lonicera, Spiraea, Diervillea,
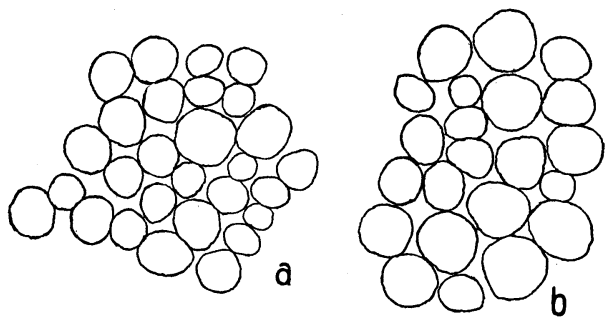

Fig. 8. Syringa vulgaris. Palisaden von der Blattfläche gesehen. a letztes Laubblatt, b erstes Hochblatt, c letztes Hochblatt. Vergr. 490/1.

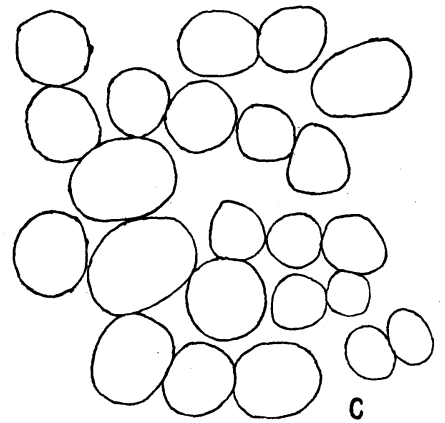

Salix), nimmt ihre Zahl pro Flächeneinheit der Blattspreite mit der Insertionshöhe der Blätter ab.

In der Reihe der Hochblattformen (Syringa vulgaris, Syringa Emodi, Rhus Cotinus, Ligustrum vulgare, Hydrangea paniculata, Weigelia amabilis Carr., Spiraea Douglaii, Rhododendron praecox, Rubus plicatus,

1) Bezieht sich auf $L(n)$. 
Kelchblattspreiten von Rosa und Mespilus germanica) ergibt sich in vielen Beziehungen die umgekehrte Folge wie bei den basalen Übergangsblättern. Einerseits werden die Palisadenzellen mit zunehmender Insertionshöhe der Hochblattformen lockerer angeordnet (Rhus, Ligustrum, Syringa vulgaris, Syringa Emodi, Weigelia, Rosa), häufig auch dicker und gedrungener (Ligustrum, Syringa vulgaris, Weigelia) (Fig. 8), andererseits wird das Schwammparenchym meist dichter und die armartigen Fortsätze seiner Zellen seltener (Syringa vulgaris, Rhus, Ligustrum, Rhododendron, Rosa), was auch Kühlhorn (pag. 121) bei den von ihm untersuchten Pflanzen findet.

Eine Ausnahme von diesem Verhalten zeigen die letzten Deckblättchen einiger Pflanzen. So fehlt bei Weigelia in der ganzen Spreite des letzten Hochblattes, bei Hydrangea (Fig. 9) in der Basishälfte desselben das Palisadengewebe vollkommen, nur typisch ausgebildetes Schwammparenchym ist vorhanden. Im auffallenden Gegensatz hierzu zeigt sich im letzten Deckblättchen von Syringa Emodi, und auch in der besonnten Spitze desjenigen von Ligustrum die Tendenz, alle Mesophyllschichten palisadenartig auszubilden.

Der Mesophyllquotient der Hochblattformen
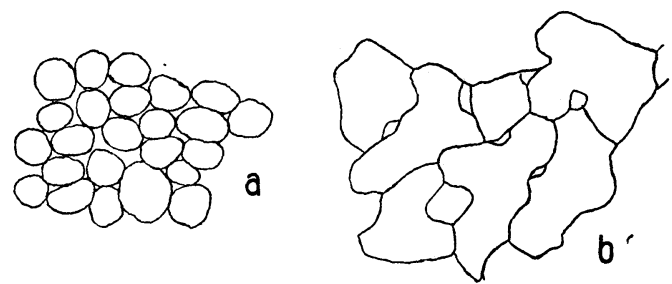

Fig. 9. Hydrangea paniculata. Zweites Hochblatt. Oberste Mesophyllschicht von der Blattfläche gesehen. $a$ in $2 / 3^{-}, b$ in $1 / 3$ Blattlängenentfernung von der Basis. Vergr. $490 / 1$. nimmt bei allen untersuchten Pflanzen - mit Ausnahme von Rhus und Syringa Emodi mit der Insertionshöhe ab, und zwar beruht diese Abnahme in der Mehrzahl der Fälle darauf, daß das Palisadenparenchym sproßaufwärts in weit höherem Maße an Dicke abnimmt als das Schwammparenchym; bei einigen Pflanzen indessen (Rubus, Mespilus, in geringerem Maße bei Syringa vulgaris und Ligustrum) findet sogar neben der Dickenabnahme des Palisadenparenchyms eine absolute Zunahme der Dicke des Schwammparenchyms statt (s. Tabelle VII, pag. 178).

Ebenso wie in den basalen Übergangsblättern ist übrigens in den Hochblattformen (Spiraea Douglasii, Neillia, Hydrangea, Rubus) die Masse der Kristalldrusen bzw. Raphidenbündel bedeutend größer als in den Laubblättern, und auch hinsichtlich der Verteilung des Chlorophylls sind sich beide Blattarten ähnlich, da dies in den höher stehenden Hochblattformen häufig gleichmäßig über das ganze Mesophyll verteilt ist. 
Tabelle VII.

\begin{tabular}{|c|c|c|c|c|c|c|c|c|c|c|c|c|}
\hline & \multicolumn{4}{|c|}{ Weigelia amabilis Carr. } & \multicolumn{4}{|c|}{ Syringa vulgaris } & \multicolumn{4}{|c|}{ Rubus plicatus } \\
\hline & 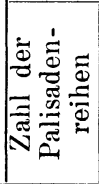 & 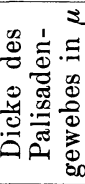 & 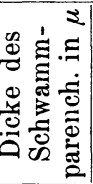 & 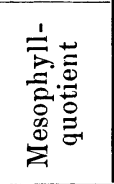 & 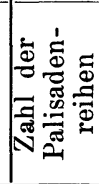 & 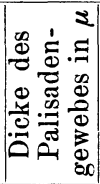 & 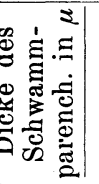 & 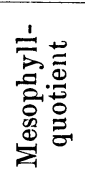 & 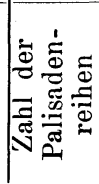 & 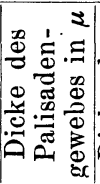 & 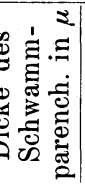 & 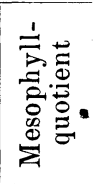 \\
\hline $\begin{array}{l}\mathrm{L}(\mathrm{n}) \\
\mathrm{H}(1)\end{array}$ & $\begin{array}{c}2(3) \\
2 \\
1(2) \\
0-1 \\
0\end{array}$ & $\begin{array}{c}119 \\
71,5 \\
33 \\
0-35 \\
0\end{array}$ & \begin{tabular}{c|}
126 \\
121,5 \\
93 \\
135 \\
128
\end{tabular} & $\begin{array}{c}0,9 \\
0,6 \\
0,35 \\
0-0,35 \\
0\end{array}$ & $\begin{array}{c}2 \\
2 \\
2 \\
1-2\end{array}$ & $\begin{array}{r}130 \\
115 \\
68 \\
43\end{array}$ & $\begin{array}{l}67 \\
79 \\
60 \\
81\end{array}$ & $\begin{array}{l}1,9 \\
1,5 \\
1,1 \\
0,6\end{array}$ & $\begin{array}{l}2 \\
2 \\
2 \\
2 \\
2(1)\end{array}$ & $\begin{array}{l}82 \\
67 \\
55 \\
42,5\end{array}$ & $\begin{array}{l}24 \\
23 \\
23 \\
32\end{array}$ & $\begin{array}{l}3,5 \\
2,9 \\
2,4 \\
1,4\end{array}$ \\
\hline
\end{tabular}

Im allgemeinen gewinnt man, wenn man die Resultate von Schramm und Nordhausen (pag. 487) mit in Betracht zieht, von den
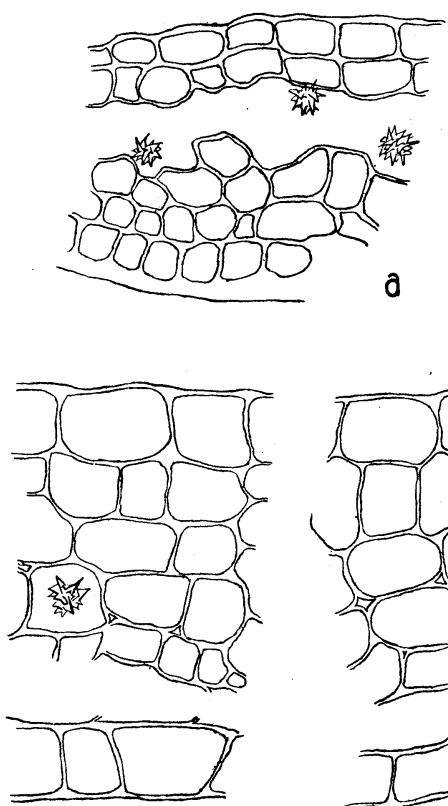
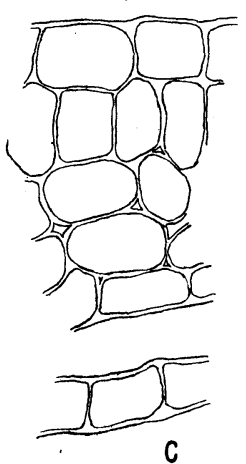
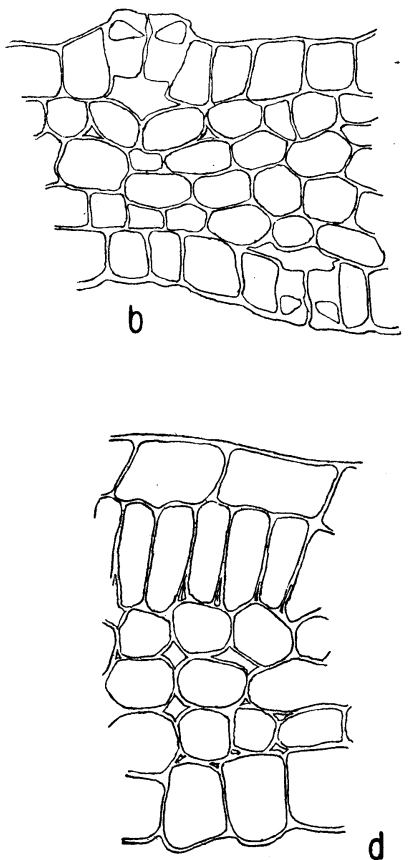

Fig. 10. Lonicera Caprifolium. Blattquerschnitt. a 1. Übergangsblatt, b 3. Übergangsblatt, c apikale Hälfte des 4. Übergangsblattes, d basale Hälfte des 4 . Übergangsblattes. Vergr. $490 \%$.

Strukturänderungen des Mesophylls in der Gesamtreihe der laubblattförmigen Gebilde am Sproß die Vorstellung; daß derMe s o ph yll qu o tie nt 
von den basalen Übergangsblättern an bis zur oberen Grenze der Laubblattzone stetig zunimmt und darauf in der Region der Hochblattformen gleichmäßig wieder sinkt, daß die Veränderung der Dichte des Palisadengewebes durch eine ähnliche Kurve dargestellt wird, während umgekehrt bis zu einem gewissen Grade die Dicke der einzelnen Palisaden mit ihrer Längenzunahme sinkt, mit ihrer Längenabnahme wieder größer wird.

\section{Zusammenfassung und Diskussion der Tatsachen.}

Beim Verfolg der Zwischenformen, die nach Gestalt und Größe
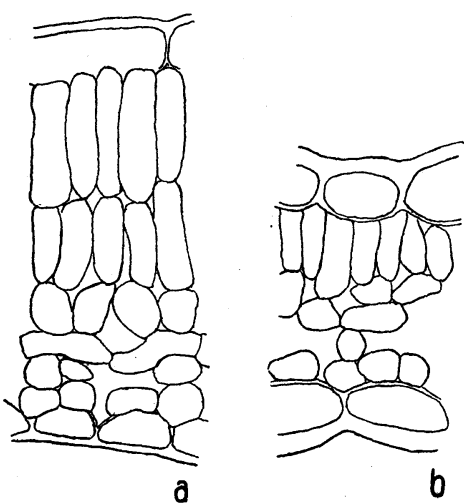

Fig. 11. Rosa (Kulturform), Blattquerschnitt. a Endfieder eines hoch inserierten Laubblattes, b Kelchspreite (3) (Länge 10,5 mm, Breite $1,5 \mathrm{~mm})$. Vergr. ca. $490 / 1$. den allmählichen Übergang z wis chen Tegmenten und Laubblättern vermitteln, waren wir von der Erwartung ausgegangen, daß sich auch in anatomischer Hinsicht eine gleichmäßig fortschreitende Veränderung feststellen lasse. Würden wir im voraus versucht haben, uns in groben Zügen ein Bild von diesen Strukturänderungen zu entwerfen, so dürfte dies derart ausgefallen sein, daß die Strukturmerkmale der Anfangsund Endpunkte der Übergangsblattreihe, eben die der Tegmente und Laubblätter sich in dieser selbst im Sinne des Übergangs wiederfinden. Überblicken wir nun die wirklichen Tatsachen, so sehen wir jedenfalls, daß zwar viele, doch durchaus nicht sämtliche Strukturänderungen in der Reihe der Übergangsblätter innerhalb des Rahmens dieser unserer Erwartungen liegen.

Ich fasse zunächst kurz diejenigen Strukturänderungen zusammen, die offenbar nichts Neuartiges darstellen. Der Übergang vollzieht sich im älteren Teil der Reihe der Zwischenformen in der Weise, daß prägnante Tegmentmerkmale verschwinden ${ }^{1}$ ): die Blattdicke wird geringer,

1) Schon die inneren Tegmente zeigen gegenüber den äußeren in anatomischer Hinsicht eine Vereinfachung, wie man bereits aus den speziellen Arbeiten über Knospenschuppen ersehen kann (vgl. Grüß, Fig. 1-37). Die äußeren Tegmente stellen eben im Gegensatz zu ihrem morphologisch einfachen Charakter eine extreme Anpassung an ihre Spezialfunktion dar, und es ist eigentlich nicht recht zu verstehen, wenn hierin Brick nach seiner vorläufigen Mitteilung (pag. 385) offenbar etwas Neues zu sehen glaubt. 
die Wände der Epidermis und des Grundgewebes werden allmählich dünner, in diesem treten des weiteren kleine Interzellularen auf, während die großen Luftspalte verschwinden nnd zugleich die Kristalldrusen seltener werden, für die die Tegmente offenbar als Ablagerungsstätte dienten, nimmt mit der Blattgröße meist auch die Größe der Zellen bis zur Grenze der Laubblattregion hin zu. Umgekehrt bereitet sich, besonders in den jüngeren Übergangsblättern, die strukturelle Formung des Laubblattes vor: bei wiederum zunehmender Blattdicke differenziert sich das zunächst isolaterale Mesophyll, oft erst nach Umwegen, zu oberseitigem Palisadengewebe und unterseitigem Schwammpyrenchym, dabei verschiebt sich das Dickenverhältnis beider Gewebe sproßaufwärts ganz allmählich zugunsten des Palisadenparenchyms, gleichzeitig steigt auch mit wachsender Assimilationstätigkeit der Übergangsblätter sproßaufwärts ihr Chlorophyllgehalt und die Gesamtmenge der Spaltöffnungen beider Blattseiten.

Es vollziehen sich indessen manche Strukturänderungen inder aufwärts verfolgten Reihe der basalen Übergangsblätter, die wir weder im Bau der Tegmente noch in dem der Laubblätter begründet finden. Dies gilt vor allem für die Art, wie sich bei vielen Pflanzen die Anordnung der Spaltöffnungen auf den Blättern dieser Reihe ändert: während auf den Knospenschuppen und Laubblättern dieser Pflanzen Spaltöffnungen oberseits entweder überhaupt fehlen oder doch nur spärlich sind, ist die Zahl oberseitiger Spaltöffnungen auf den Übergangsblättern relativ groß, derart, daß eine die Zahl der oberseitigen Spaltöffnungen darstellende Kurve ein Maximum innerhalb der Übergangsblattreihe aufweisen und von hier nach beiden Seiten abfallen würde. Hierbei fällt ein bestimmtes Abhängigkeitsverhältnis zwischen den oberseitigen Spaltöffnungen und den Palisaden auf: bei allen untersuchten Pflanzen, auf deren basalen Übergangsblättern oberseitige Spaltöffnungen vorkommen, treten in diesen Palisaden nie auf, solange die Zahl der Spaltöffnungen auf der Oberseite größer ist als die stetig zunehmende Zahl derselben auf der Unterseite.

Wie die Anordnung der Spaltöffnungen ändert sich auch die Dichte der Behaarung von den Tegmenten zu den Laubblättern in eigenartiger Weise, indem die Zahl der Haargebilde zunächst deutlich wächst, dann wieder nach der Laubblattregion hin abnimmt.

Weiterhin dürfte auch der Umstand Beachtung finden, daß nicht erst die typischen Laubblätter, wie man etwa denken könnte, sondern bereits die jüngsten Übergangsblätter, im Gegensatz zu den Tegmenten und älteren Übergangsblättern, meist recht stark wellenförmigen Verlauf 
der radialen Epidermiswände aufweisen, derart, daß das Maximum der Wellung an der Grenze der basalen Übergangs- und der Laubblätter, oder sogar tiefer in der Zone der Übergangsblätter selbst liegt.

Wie ich mich an den Beispielen von Ligustrum vulgare und Syringa v ulgaris überzeugte, treten übrigens diese typischen Merkmale der basalen Übergangsblätter (z. B. oberseitige Spaltöffnungen, Epidermiswellung) auch auf dem ersten Blatt von solchen Sprossen auf, die, entweder infolge des Zurückschneidens oder unter normalen Verhältnissen, aus der Achsel von Blättern derselben Vegetationsperiode entspringen.

Bezüglich des Mesophylls der basalen Übergangsblätter schließlich tritt die Tatsache hervor, daß die Palisaden in den jüngeren Übergangsblättern recht locker stehen, meist lockerer als im untersten Laubblatt.

Wir sehen also, daß einige Merkmale sich bei den Übergangsblättern in maximaler Form repräsentieren und durchaus nicht eine gleichmäßig fortschreitende Stufenfolge der Ausbildung durchmachen.

Bei den Hochblattformen läßt sich im voraus eine bestimmte Vorstellung über die zu erwartenden Strukturänderungen nur schwer bilden. Da die Blattformen nach oben zu einfacher und kleiner werden, könnte man ähnliche Bauverhältnisse wie bei den Übergangsblättern an der Sproßbasis mutmaßen und der Oberflächenverkleinerung entsprechend auch eine Reduktion der inneren Teile erwarten. Andererseits würde man bei ihnen extremen Lichtblattcharakter zu finden erwarten, wenn man sich die Veränderungen, die sich beim Verfolg der Laubblattreihe ergeben, in die Reihe der Hochblattformen hinein fortgesetzt denkt und die, immerhin intensive Beleuchtung dieser Blattformen an der Peripherie der Pflanze mit in Betracbt zieht.

Im Sinne einer Reduktion würde es liegen, daß die Dicke in der Tat zugleich mit der Blattgröße nach der Sproßspitze zu abnimmt und gleichzeitig die Zellen kleiner werden, während umgekehrt die Tatsache, daß die Behaarung in ungleich höherem Maße als die Zahl der Epidermiszellen wächst, für einen xerophileren, lichtblattartigen Charakter dieser Blattformen spricht.

Daneben finden wir beim Verfolg der Hochblattformen nun auch Strukturänderungen, die nicht in der Linie unserer Erwartungen liegen. So nimmt im Gegensatz zur Vermehrung der Epidermiszellen die Zahl der Spaltöffnungen stark ab, vor allem wird ihre Anordnung eine andere, indem sie häufig auch oberseits auftreten, bei den letzten Hochblättern oft ebenso zahlreich wie unterseits, während die Laubblätter gar nicht oder nur spärlich oberseitige Spaltöffnungen tragen. 
Ferner weisen die Hochblattformen oft ein charakteristisches Merkmal auf, das in der Laubblattreihe bei ihrem Verfolg sproßaufwärts ganz verschwunden war: ihre radialen Epidermiswände verlaufen bei einer Anzahl von Pflanzen wellenförmig, um so stärker, je höher das Blatt steht.

Die Strukturänderungen des Mesophylls lenken insofern die Aufmerksamkeit auf sich, als nicht etwa mit abnehmender Blattdicke eine gleich starke Reduktion beider Komponenten, sowohl des Palisaden- als auch des Schwammparenchyms eintritt, so daß also der Mesophyllquotient gleich bleiben würde, sondern daß vielmehr das Dickenverhältnis beider Gewebe sich sproßaufwärts stetig zugungsten des Schwammparenchyms verschiebt; gleichzeitig werden die einzelnen Palisaden dicker und stehen meist auch lockerer.

Bei allen diesen Tatsachen fällt es auf, wie außerordentlich ähnlich die Hochblattformen, auch in den neuartig erscheinenden Eigenschaften, den basalen Übergangsblättern sind, soweit diese nicht noch irgendwie tegmentartig modifiziert erscheinen.

Wenn so die basalen Übergangsblätter und die Hochblattformen Merkmale schlechthin aufweisen können, die aus der Struktur der Tegmente oder Laubblätter nicht zu erschließen sind, oder wenn sie einige, an diesen vorhandene Merkmale in solcher Ausprägung oder Anordnung zeigen, wie man sie weder bei Zwischenformen zwischen Tegmenten und Laubblättern bzw. bei die Laubblattreihe gewissermaßen fortsetzenden Formen erwarten würde, noch auch etwa an unfertigen Entwicklungsstadien des Laubblattes finden könnte, dann darf man sie in anatomischer Beziehung als etwas schlechterdings Neuartiges gegenüber den Tegmenten und Laubblättern auffassen. Nicht nur die äußeren Tegmente also, wie Brick (pag. 385) meint, sondern auch die Übergangsblätter der Sproßbasis und die Hochblattformen weisen eine spezifische ,Andersentwicklung ${ }^{6}$ gegenüber dem Laubblatt auf: sie sind keine reinen Hemmungsbildungen, keine stehen gebliebenen Stadien der Laubblattentwicklung, sondern sie haben einen Entwicklungsweg eingeschlagen, der von dem des Laubblattes von einem bestimmten Stadium ab divergiert und zu einem besonderen, individuellen Blattgebilde führt.

Wir haben uns nun die Frage vorzulegen, wodurch die von der Laubblattstruktur abweichenden, besonderen Bauverhältnisse der basalen Übergangsblätter und der Hochblattformen bedingt werden und kommen damit zunächst zur Erörterung der Beziehungen, die zwischen den Strukturen dieser Blattgebilde einerseits und ihren Funktionen und äußeren Lebensbedingungen andererseits etwa bestehen. 
Wir dürfen davon ausgehen, daß die Funktionen der basalen Übergangsblätter und der Hochblattformen bei den untersuchten Pflanzen im Prinzip die gleichen sind: für beide Arten von Blattgebilden handelt es sich, wie schon pag. 158 hervorgehoben ist, wesentlich darum, die jüngeren Sproßteile während ihrer Entwicklung zu schützen; hierzu kommt als Nebenfunktion die Assimilationstätigkeit.

Als Ausdruck der Schutzfunktion beider Blattarten ist es anzusehen, daß die Haare bzw. Kolleteren auf ihnen merklich dichter stehen als auf den Laubblättern.

Eben durch die Schutzfunktion der basalen Übergangsblätter und der Hochblattformen wird auch eine ziemlich steile Orientierung derselben gefordert, solange die Achse des zu schützenden Sprosses noch nicht gestreckt ist und sie selbst auch noch nicht ganz ausgewachsen zu sein pflegen; später, im ausgewachsenen Zustand, nimmt die Spreite dieser Blattgebilde bis zum frühen Abfall eine mehr horizontale Lage ein, zeigt aber gegenüber der Lichtrichtung eine gewisse Indifferenz und Starrheit der Orientierung; in einzelnen Fällen mag sie dauernd ihre Rückseite dem Lichte zukehren.

Nun sind ja besagten Blattformen bestimmte Merkmale eigentümlich, die als Abschwächung des dorsiventralen Blattcharakters aufgefaßt werden dürfen: die Spaltöffnungen sind oft auf beiden Seiten gleich zahlreich, die Epidermen gleich dick, das Chlorophyll ist in allen Mesophyllschichten oft gleich verteilt, die Palisaden stehen lockerer und sind gedrungener, das Schwammparenchym ist dichter. Man wird geneigt sein, diese Eigentümlichkeiten auf die zeitweise andere Orientierung der gerichteten äußeren Faktoren (Beleuchtung, Luftbewegung) zurückzuführen, welche durch die oben erwähnte Schrägstellung der besagten Blattgebilde während der Sproßentwicklung bedingt wird, und ich bin der Ansicht, daß in der Tat solche Beziehungen gelten, allerdings, wie wir sehen werden, nur bis zu gewissen Grenzen. Welcher Art übrigens diese Beziehungen sind, darüber läßt sich zurzeit allerdings nichts Gewisses aussagen. Sicher ist aber anzunehmen, daß eine direkte, kausale Einwirkung jener Faktoren nur eine untergeordnete Rolle spielt, denn bezüglich eines jener besprochenen Merkmale, nämlich bezüglich des Auftretens oberseitiger Spaltöffnungen konnte nachgewiesen werden, daß es, jedenfalls auf den unteren Übergangsblättern, schon in der Knospe angelegt ist, und daß bei im Dunkeln ausgetriebenen Knospen von Syringa vulgaris, Ligustrum vulgare und Lonicera Caprifolium auf den basalen Übergangsblättern ebensoviele oberseitige Spaltöffnungen ausgebildet werden wie auf normal belichteten. Es ist anzunehmen, daß 
im wesentlichen das gleiche auch für die übrigen hier in Betracht kommenden Merkmale gilt, obwohl leider entsprechende Beobachtungen nicht gemacht werden konnten. Die Annahme ist um so mehr berechtigt, als wir aus neueren Arbeiten wissen (s. Nordhausen, pag. 483), daß auch bei den Laubblättern die Einwirkung der augenblicklichen äußeren Faktoren nur eine beschränkte ist.

Es ist beachtenswert, daß die basalen Übergangsblätter und die Hochblattformen Eigenschaften zeigen, die als Schattenblattmerkmale bezeichnet und als solche für gewöhnlich nur mit dem Begriff des Laubblattes verknüpft werden, ja, daß sie diese nicht nur schlechthin, sondern in stärkerem Maße als das typische Schattenlaubblatt selbst aufweisen können; ich erinnere nur an die geringe Blattdicke, an die Epidermiswellung, den niedrigen Mesophyllquotienten, die lockere Anordnung der relativ dicken und kurzen Palisaden. Für den Schattenblatthabitus speziell der Hochblattformen zeugt auch die Reduktion der Epidermispapillen auf der Unterseite der Hochblätter von Syringa Emodi, die offenbar als Schattenblattmerkmal anzusehen ist ${ }^{1}$ ) (s. Nordhausen, pag. 499).

Wenn wir berücksichtigen, daß die Lebensbedingungen der basalen Übergangsblätter und der Hochblattformen bei gleicher Funktion doch mannigfaltige Verschiedenheiten zeigen, so muß diese durchgehende prinzipielle Ähnlichkeit beider Blattarten besonders auffällig erscheinen. Insbesondere aber mußder typisch schattenblattartige Charakter mancher Hochblätter die Aufmerksamkeit auf sich lenken. Denn zweifellos sind sie intensiver belichtet als die basalen Übergangsblätter und selbst auch als die Laubblätter. Daran ändert nichts, daß in einigen Fällen eine geringe Beschattung durch Blütenteile stattfinden kann, zumal dies nur während der vollen Entwicklung der Blüten zutrifft. Ferner sind gerade an der Peripherie der Pflanze, also bei den Hochblättern, infolge der größeren Lufttrockenheit und der stärkeren Luftbewegung die Transpirationsbedingungen am günstigsten. Bei solchem Gegensatz zwischen Struktur und äußeren Lebensbedingungen können wir unbedenklich sagen, daß für jene nur innere Faktoren verantwortlich zu machen

1) Es tauchte die Vermutung auf, auch die Tatsache, daß auf manchen basalen Übergangblättern und Hochblattformen anormalerweise oberseitige Spaltöffnungen auftreten, sei analog den übrigen besonderen Eigenschaften besagter Blattformen als Schattenblattmerkmal, also (Schramm, Nordhausen) als Primärblattmerkmal aufzufassen. Eine Untersuchung der Primärblätter von Syringa vulgaris und Ligustrum vulgaris zeigte indessen, daß diese Vermutung nicht zutrifft. 
sind. Wir haben damit eine Tatsache vor uns, die für das Problem der Licht- und Schattenblätter neben den neueren Erfahrungen von einiger Bedeutung sein dürfte.

Da an vers chiedenen Sproßteilen, nämlich an der Basis und an der Spitze, mit einer Verminderung der Blattgröße und Vereinfachung der Form derartig gleiche und zum Teil befremdende Strukturbesonderheiten gegenüber dem Laubblatt verknüpft sind und diese um so deutlicher auftreten, je mehr die Blattgröße abnimmt, so lag es nahe, engere Beziehungen zwischen Größe und Struktur anzunehmen.

Um diese Beziehungen zu prüfen, wurden einige besonders in der Größe voneinander abweichende Blattgebilde untersucht, die, um Ungleichheiten in der Wirkung der äußeren Faktoren auszuschalten, dicht benachbart und gleich gut belichtet sein mußten. Als solche wurden die recht verschieden großen Kelchzipfel von Mespilus germanica und Rosa ausgewählt, die, wie erwähnt (pag. 160), bei beiden Pflanzen um so kleiner werden, je höher sie in der Blattstellungsschraubenlinie stehen. Bei dieser Untersuchung ergab sich ungefähr ein Strukturbild, als ob man Hochblattformen auf die gleiche Insertionshöhe zusammengedrängt hätte. Es zeigte sich nämlich, daß mit abnehmender Blattgröße die Blattdicke sank, daß ferner der Mesophyllquotient niedriger (siehe Tabelle VIII, pag. 186) und gleichzeitig das Palisadengewebe lockerer wurde. Beim Fehlen oberseitiger Spaltöffnungen auf den Laubblattspreiten waren solche auf den untersuchten Blattformen um so zahlreicher, je kleiner die letzteren erschienen - allerdings waren die absoluten Zahlenwerte in allen Fällen nicht groß (s. Tabelle V, pag. 171). Weiterhin wurde die Behaarung, wo sie überhaupt auftrat (Mespilus), mit der Abnahme der Blattgröße dichter, und endlich zeigten die kleineren Blätter in höherem Grade die Tendenz der Epidermiswellung; auch das ist noch erwähnenswert, daß die Zellgröße mit der Blattgröße sank. Interessant ist ferner, daß ganz ähnliche Unterschiede, abgesehen vom Auftreten oberseitiger Spaltöffnungen, sich herausstellten beim Vergleich des letzten extrem kleinen Laubblattes von der Spitze eines Sprosses von Betula pendula mit dem voraufgehenden Laubblatt.

Alle diese bei Mespilus, Rosa und Betula aufgefundenen Strukturdifferenzen der verschieden großen Blätter lassen sich weder auf Unterschiede der Funktion noch auf solche der äußeren Faktoren zurückführen, es kommen allein innere Faktoren in Betracht, die offenbar mit der Entwicklungsfolge der Blätter am Vegetationspunkt bzw. mit der Blattgröße zusammenhängen; wir werden also annehmen dürfen, daß 
Paul Neese,

Tabelle VIII.

\begin{tabular}{|c|c|c|c|c|c|c|c|c|}
\hline & \multicolumn{4}{|c|}{ Rosa (Kulturform) } & \multicolumn{4}{|c|}{ Mespilus germanica } \\
\hline & 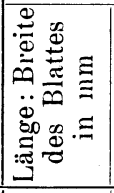 & 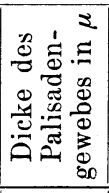 & 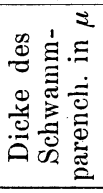 & 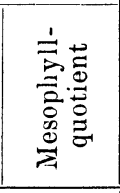 & 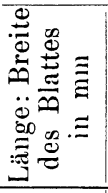 & 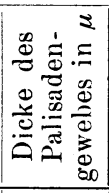 & 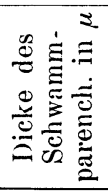 & 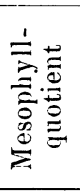 \\
\hline $\begin{array}{ll}\text { Laubblatt } & \\
\text { Kelchspreite } & (1) \\
", & (2) \\
" & (3) \\
" & (4)\end{array}$ & $\begin{array}{l}54: 37 \\
55: 21 \\
12: 2,5 \\
10: 1,5\end{array}$ & \begin{tabular}{|c|}
80 \\
82 \\
$34(46)$ \\
23
\end{tabular} & $\begin{array}{c}44 \\
57,5 \\
52(36) \\
37\end{array}$ & $\begin{array}{c}1,8 \\
1,45 \\
0,65(1,3) \\
0,6\end{array}$ & $\begin{array}{l}84: 32 \\
37: 7,5 \\
\\
23: 2\end{array}$ & $\begin{array}{l}86 \\
54\end{array}$ & $\begin{array}{l}68 \\
48,5\end{array}$ & $\begin{array}{l}1,7 \\
1,1\end{array}$ \\
\hline
\end{tabular}

die letztere auch bei den Struktureigentümlichkeiten der basalen Übergangsblätter und der Hochblattformen eine Rolle spielt.

In Parallele hierzu können wir nach dem Vorgange Anheißer's (pag. 87) die Epidermiswellung mit der geringen Dicke des Spreitenteils in Verbindung bringen. da wir sie überall da auftreten sehen, wo die Blattdicke gering ist, und können sie dann eventuell als Mittel zur Erhöhung der mechanischen Festigkeit ansehen.

Die vorliegenden Untersuchungen wurden während des Wintersemesters 1912/13 und des Sommersemesters 1913 im botanischen Institut der Universität Kiel ausgeführt. Es ist mir eine angenehme Pflicht, Herrn Geheimrat Prof. Dr. Reinke, sowie Herrn Prof. Dr. Nordhausen für die Anregungen und Ratschläge, durch die sie mich in meiner Arbeit unterstützt haben, an dieser Stelle meinen herzlichen Dank auszusprechen.

\section{Literatur.}

A d lerz, E., Bidrag till knopffjällens anatomi hos träd och Buskartade växter. Bihang till Kongl. Svenska vet.-akad. Handlinger 1881, Bd. VI.

Anheißer, R., Über die arunkoïde Blattspreite. Flora 1900, Bd. LXXXVII.

Brick, Eduard, Die Anatomie der Knospenschuppen in ihrer Beziehung zur Anatomie der Laubblätter. Kurze Mitt., Ber. d. D. bot. Ges. 1903, Bd. XXXI.

Cadura, Richard, Physiologische Anatomie der Knospendecken dikotyler Laubbäume. Inaug.-Diss., Breslau 1886.

Espe, William, Beiträge zur Kenntnis der Verteilung der Spaltöffnungen über die Blattspreite. Inaug.-Diss., Göttingen 1911.

Feist, Aug., Über die Schutzeinrichtungen der Laubknospen dikotyler Laubbäume. Nova acta 1887 , Bd. LI.

Goebel, K., Beitriige zur Morphologie und Physiologie des Blattes. Bot. Zeitg. 1880, Bd. XXXVIII. 
Zur Kenntnis d. Struktur d. Niederblätter u. Hochblätter einiger Laubhölzer. 187

Grüß, Joh., Beiträge zur Biologie der Knospe. Pringsh. Jahrb. f. wissensch. Bot. 1892, Bd. XXIII.

Henry, Knospenbilder. Nova acta 1847, Bd. XIV, pars 1.

Kühlhorn, Zur Kenntnis des Baues der Laubblätter der Dikotylen. Inaug.-Diss., Göttingen 1908.

Lubbock, John, On Stipules, their forms and functions. Journ. of the Linnean Society, Botany, Vol. XXVIII, XXX, London 1891, 1895.

Ders., On buds and stipules. Journ. Linn. Soc. Bot. 1897-98, Vol. XXXIII.

Ders., On buds and stipules. London 1899.

Mikosch, Karl, Beiträge zur Anatomie und Morphologie der Knospendecken dikotyler Holzgewächse. Sitzungsber. d. Kais. Akad. d. Wiss., Bd. LXXIV, Abt. 1, mathem.-naturw. Klasse, Wien 1876.

Nordhausen; Max, Über Sonnen- und Schattenblätter, 2. Mitteilung. Ber. d. D. bot. Ges. 1912, Bd. XXX.

Schramm, Richard, Über die anatomischen Jugendformen der Blätter einheimischer Holzpflanzen. Separatum aus Flora 1912, Bd. CIV.

Schumann, C. G. R., Anatomische Studien über die Knospenschuppen von Koniferen und dikotylen Holzgewächsen. Bibl. bot. Kassel 1889.

Schumann, Karl, Praktikum für morphologische und systematische Botanik. Jena 1904.

Yapp, R. H., Spiraea Ulmaria L. and its bearing on the problem of xeromorphy in Marsh plants. Annals of botany 1912, Bd. XXVI. 